Sharif University of Technology
Scientia Iranica
Transactions E: Industrial Engineering
hCIENTIA

\title{
Performance measurement in the health care sector: A leader-follower network DEA model based on double frontier analysis
}

\author{
E. Vaezi* \\ Department of Industrial Engineering, Science and Research Branch, Islamic Azad University, Tehran, Iran. \\ Received 7 June 2019; received in revised form 22 February 2020; accepted 15 June 2020
}
KEYWORDS
Network DEA;
Medical diagnostic
laboratories;
Sustainability;
Non-cooperative
game;
Double-frontier;
Additional inputs;
Undesirable outputs;
k-means algorithm.

\begin{abstract}
Efficiency evaluation for laboratories as one of the most significant areas of healthcare plays a key role in enhancing the quality of laboratory management. In this paper, a three-stage structure with optimal desirable and undesirable inputs and outputs was taken into consideration. This network comprises a leader and two followers. The suggested model simulates the internal structure of a diagnostic lab (pre-test, test, and post-test). The evaluation criteria are determined using the Fuzzy Delphi technique. Due to the environmental, economic, and social impacts of healthcare systems, the significance of sustainability criteria is obvious in the case study indicators. The non-cooperative methodbased multiplicative Data Envelopment Analysis (DEA) technique is used to evaluate the efficiency of the network from both optimistic and pessimistic views. Moreover, a heuristic technique is employed to convert non-linear models into linear ones. Finally, a k-means method is proposed to cluster Decision-Making Units (DMUs) into several groups with similar characteristics based on double-frontier standpoint.
\end{abstract}

(C) 2022 Sharif University of Technology. All rights reserved.

\section{Introduction}

Currently, Medical Diagnostic Laboratories (MDLs) play a significant part of the health organization in the real world. They have a vital role in the domains of healthcare, diagnosis, maintenance, and prevention of different illnesses. Based on global standards, the share of MDLs in the healthcare market is about $5.6 \%$, which represents a significant contribution. Due to the economic, social, and environmental situations of the MDLs, there is a growing public demand for highquality performance, reduced functional costs, and enhanced quality of such organizations. Efficacy as

\footnotetext{
*.E-mail address: ehsan.vaezi@srbiau.ac.ir
}

the main pillar of growth is one of the most commonly used mechanisms for evaluating the performance of a healthcare system including MDLs. Therefore, it is of special significance to survey the performance of MDLs by appraising efficiency and productivity. Therefore, we can gauge the efficiency and inefficiency of the Decision-Making Units (DMUs). In this respect, the weaknesses can be reduced while the strengths increase. Likewise, optimal use of available resources occurs. Throughout the past years, the role of the MDLs in the healthcare sector has made a significant progress and the tasks of Sohn et al. [1] and Fang et al. [2] are significant in this respect. In order to evaluate the effectiveness of MDLs, a proper tool needs to be used. Throughout the past years, numerous models were suggested to evaluate the performance of MDLs using two general parametric and non-parametric approaches. 
This study utilized the Network Data Envelopment Analysis (NDEA) as a nonparametric method. This technique chooses efficient DMUs and creates efficiency and inefficiency frontiers. These frontiers represent two criteria for measuring the efficiencies of other DMUs. In this research, the mentioned efficiency is measured by utilizing the DEA technique in order to meet the four following objectives:

1. DEA measures the efficiency of the system based on a logical model;

2. DEA discovers efficient and inefficient DMUs;

3. DEA determines the degree of inefficiency of the DMUs;

4. DEA specifies the patterns of inefficient DMUs [3].

Since MDLs contain three levels (pre-test, test, and post-test) and are of multi-stage nature, the current study applies NDEA models to evaluate efficiency. This study considers a three-stage network with additional undesirable inputs and outputs. In fact, DEA is proposed as a theoretical framework for performance analysis, but its application in the field of healthcare has very low. This network is proposed to evaluate the performance and ranking of laboratory units based on sustainability criteria (economic, social, and environmental). Thus, a three-stage network of three laboratory processes is designed. In this respect, the pre-test process involves the reception unit and the sample unit. The test process involves a test unit, while the post-test process involves the test result unit. The case study includes 25 MDLs in Tehran in the real world and subsequently, shall analyze the results from the double-frontier viewpoint. The structure of this paper is rendered as follows: Section 2 reviews the literature on the DEA method. Section 3 discusses the research methodology. Then, the mathematical modeling of the problem is described. Section 4 introduces a heuristic approach to solve the nonlinear program. Section 5 comprises the result of a case study proposed in this research. Lastly, Section 6 concludes the paper.

\section{Literature review}

Currently, efficiency measurement is an extremely crucial issue for a better understanding of problems in a system and planning for future improvement [4]. DEA is one of the most important and appropriate approaches to measuring the performance of DMUs [5]. DEA objectives are to measure efficiency and present efficient and inefficient units. Efficient units generate the maximal amount of outputs from the minimal amount of inputs and their efficiency equates to (1). These units form the efficiency frontier, while other units with the efficiency range of (0 to 1$)$ are identified as inefficient ones. DEA enjoys the capacities in which each DMU is considered in segregation, and it conducts efficiency appraisal on the basis of the distance between this unit and the efficiency frontier [6].

Farrell [7] considered a model for performance evaluation for the first time. Charnes et al. [8] developed Farrells' model and dubbed it as CCR (CharnesCooper-Rhodes DEA model). Then, Banker et al. [9] developed DEA and proposed BCC (Banker-CharnesCooper Model). DEA is a non-parametric linear programming model that evaluates the performance of a set of homogeneous DMUs with several inputs and outputs [10]. In classical DEA models such as the CCR and BCC models, we do not consider the intermediate measures of DMUs or internal operations of DMUs and measure the efficiencies of DMUs as a "Black Box" [11]. In fact, the efficiency analysis in this method is carried out by the initial inputs and the final outputs. Ignoring the internal structure of systems would instead leave us with the classical DEA models where important information and segregation between the efficient units cannot be presented [12]. To overcome the problem, Fare and Grosskopf [13] suggested a NDEA model. In the NDEA models, the internal structure of systems and internal interactions of DMUs are taken under consideration until the accuracy of efficiencies is increased. Kao [14] categorized the network models into three sets, namely series, parallel, and hybrid. Kao stated that when activities in a system were protracted with respect to each other, the system would be of a series structure; whenever activities were in a parallel form alongside each other, the system would have a parallel structure. Similarly, in the case of a hybrid condition between the series and parallel structures, a hybrid mode is engaged. The NDEA approach can simulate networks and then, estimate the efficiencies [3,15]. The internal structure of systems can be simulated using sub-DMUs in either series or parallel. Thus, the systems with series and parallel structures are two very significant areas in NDEA [15]. For the parallel structure, the sum of the inputs or outputs of all stages is considered to be representing the inputs or outputs of the whole structure. However, in the series structure, the inputs of the first stage and the outputs of the last stage are the inputs and outputs of the whole structure [16]. The general efficiency of the parallel and series structures is measured by the multiplicative and additive methods, respectively [17]. In recent years, the multi-stage efficiency evaluation remains one of the most important topics in NDEA and the parallel and series structures continue to be used by many researchers.

Kao [14] proposed a "closed system" with a series structure to be taken under consideration for intermediate measures, but without any additional input or output in each stage, whereas Yu and Lin [18] 
employed the NDEA to measure service effectiveness and technical efficiency. Kao [4] utilized the NDEA approach to evaluate the overall efficiency of the network with multi-stage and additional inputs. Cook et al. [19] used the NDEA for efficiency evaluation. In the network structure, the sub-DMUs have desirable or undesirable outputs.

The role of undesirable factors remains extremely crucial in NDEA. In recent years, Liu et al. [20] employed clustering techniques and defined this part as one of the four main parts of NDEA. For the first time, Fare et al. [21] took undesirable factors into consideration to evaluate the efficiency of DEA models. Lu and Lo [22-25] categorized the methods for undesirable outputs in NDEA in the following three modes: The first mode is to ignore the undesirable outputs that are done to simplify the models; the second mode is to measure distances so as to limit the expansion of the undesired output or that the undesired output is modeled as a nonlinear NDEA model; and the third mode involves considering the undesired output as a desired input, or employing the negative sign as a desirable output, or applying a reduction of conversion. Over the past few years, Wang et al. [26] and $\mathrm{Wu}$ et al. [27] delved into the role of undesired factors in manufacturing processes and utilized the NDEA to measure efficiency. In recent years, the transformation of unfavorable features has facilitated the use of undesirable factors in generating favorable ones. For example, in a new approach, Wu et al. [28] considered an interactive network consisting of two stages: The first stage inserts the undesirable outputs into the second stage and ultimately, and ultimately the second stage produces the desirable output and utilizes the undesirable ones for production.

In recent years, NDEA models have undergone development and the models combining this science with the game theory branch have been rendered [29]. Li et al. [30] presented an NDEA model with two stages: the part holding the upper hand is called "leader" and the other called "follower". The performance of the leader is maximized to the optimum point and thus, the performance of the follower is secured by keeping the performance of the leader constant. This instance is designated as a Stackelberg game. In another research, An et al. [31] considered a network in two stages in an interactive mode and compared the efficiency of this network in cooperative and non-cooperative modes (leader-follower mode). Zhou et al. [32] attempted to evaluate the efficiency of the performance of a multistage network in the black box and also in the noncooperative mode (leader-follower) and then, compared their results with each other. Du et al. [33] investigated the grounds of leader-follower and studied the parallel structure between the cooperative and non-cooperative modes. On the basis of the above-mentioned facts, the main difference between the black box and the network approach lies in the internal correlations of systems. Some of the previous researchers have studied bi-level programming under different situations. For instance, Maiti and Roy [34] designed a model based on bi-level programming for Stackelberg game under intuitionistic fuzzy environment. Maiti and Roy [35] presented and solved the multi-choice stochastic bilevel programming problem in the cooperative mode via fuzzy programming method. Moreover, Roy and Maiti [36,37] studied bi-level programming with multichoice programming for Stackelberg game under fuzzy and stochastic environments.

The application of DEA with a double-frontier view considers two frontiers to compute the efficiency of each DMU. These two frontiers include efficient and inefficient frontiers. The efficiency of an efficient frontier is called optimistic efficiency, whereas the efficiency of the inefficient frontier is known as pessimistic efficiency [38]. From the optimistic point of view, each DMU along with a set of efficient units that form the efficient frontier is compared. In the pessimistic view, each DMU, together with a set of inefficient units, forming the inefficient frontier is considered for the purpose of comparison [30]. The value of the optimistic view is lower than or equal to (1), whereas the efficiency of the pessimistic view is greater than or equivalent to (1). The optimistic and pessimistic efficiency values are exactly equivalent to (1) if the DMU under evaluation is placed on the efficient or inefficient frontiers, respectively $[39,40]$. However, upon calculating the optimistic efficiency, the closer the DMU proves to be to the efficiency frontier, the more desirable it will be, whereas in the case of computing the pessimistic efficiency, the further the distance of the DMU, the better and the desirability added. In fact, double frontier views each DMU from two angles and any conclusion that leans on one of these perspectives shall be biased and inadequate $[41,42]$. For the first time, Doyle et al. [43] computed the efficiency of DMUs from the optimistic and pessimistic views. In recent years, many researchers have utilized the double frontier for efficiency evaluation and presented various approaches for calculating the overall performance; in this respect, a number of tasks were designated by Wang and Chin who proposed a numerical measure for the geometrical mean efficiency [44-47].

Producing a sustainable product as a practical way to minimize the environmental impacts of a product is a significant approach to ensuring sustainability [48]. In order to assess eco-efficient performance, Chen et al. [49] recently introduced the concept of "sustainable performance". This concept explains how to achieve the desired output or lower undesired output in the process of production. Sustainability assessment is not limited to environmental criteria. 
Table 1. Classification of studies on DEA-game theory method.

\begin{tabular}{|c|c|c|c|c|c|c|c|}
\hline Reference & Type of game & $\begin{array}{l}\text { Structure } \\
\text { of network }\end{array}$ & $\begin{array}{c}\text { Additional } \\
\text { inputs }\end{array}$ & $\begin{array}{c}\text { Undesirable } \\
\text { output }\end{array}$ & $\begin{array}{c}\text { Type of } \\
\text { modelling }\end{array}$ & $\begin{array}{l}\text { Type of } \\
\text { frontier }\end{array}$ & Sustainability \\
\hline Hwang et al. [54] & Cooperative & One-stage & - & $\checkmark$ & $\begin{array}{c}\text { Linear } \\
\text { programming }\end{array}$ & $\begin{array}{c}\text { Optimistic } \\
\text { view }\end{array}$ & - \\
\hline Kao and Hwang [16] & Cooperative & Two-stage & - & - & $\begin{array}{c}\text { Linear } \\
\text { programming }\end{array}$ & $\begin{array}{l}\text { Optimistic } \\
\text { view }\end{array}$ & - \\
\hline Wang et al. [55] & Cooperative & Two-stage & - & - & $\begin{array}{c}\text { Linear } \\
\text { programming }\end{array}$ & $\begin{array}{l}\text { Optimistic } \\
\text { view }\end{array}$ & - \\
\hline Kao $[14]$ & Cooperative & Two-stage & $\checkmark$ & - & $\begin{array}{c}\text { Linear } \\
\text { programming }\end{array}$ & $\begin{array}{l}\text { Optimistic } \\
\text { view }\end{array}$ & - \\
\hline Li et al. [30] & Non-cooperative & Two-stage & $\checkmark$ & - & $\begin{array}{c}\text { Linear } \\
\text { programming }\end{array}$ & $\begin{array}{c}\text { Optimistic } \\
\text { view }\end{array}$ & - \\
\hline Liang et al. [29] & $\begin{array}{l}\text { Cooperative and } \\
\text { non-cooperative }\end{array}$ & Two-stage & - & - & $\begin{array}{c}\text { Linear } \\
\text { programming }\end{array}$ & $\begin{array}{l}\text { Optimistic } \\
\text { view }\end{array}$ & - \\
\hline Wu et al. [27] & Cooperative & Two-stage & $\checkmark$ & $\checkmark$ & $\begin{array}{c}\text { Linear } \\
\text { programming }\end{array}$ & $\begin{array}{l}\text { Optimistic } \\
\text { view }\end{array}$ & - \\
\hline Zhou et al. [32] & Non-cooperative & Two-stage & - & - & $\begin{array}{l}\text { Non-linear } \\
\text { programming }\end{array}$ & $\begin{array}{l}\text { Optimistic } \\
\text { view }\end{array}$ & - \\
\hline An et al. [31] & $\begin{array}{l}\text { Cooperative and } \\
\text { non-cooperative }\end{array}$ & Two-stage & $\checkmark$ & - & $\begin{array}{c}\text { Non-linear } \\
\text { programming }\end{array}$ & $\begin{array}{c}\text { Optimistic } \\
\text { view }\end{array}$ & - \\
\hline Wu et al. [28] & $\begin{array}{l}\text { Cooperative and } \\
\text { non-cooperative }\end{array}$ & Two-stage & $\checkmark$ & $\checkmark$ & $\begin{array}{c}\text { Non-linear } \\
\text { programming }\end{array}$ & $\begin{array}{l}\text { Optimistic } \\
\text { view }\end{array}$ & - \\
\hline Du et al. [33] & $\begin{array}{l}\text { Cooperative and } \\
\text { non-cooperative }\end{array}$ & Three-stage & - & - & $\begin{array}{c}\text { Linear } \\
\text { programming }\end{array}$ & $\begin{array}{l}\text { Optimistic } \\
\text { view }\end{array}$ & - \\
\hline Yousefi et al. [56] & Cooperative & Three-stage & $\checkmark$ & - & $\begin{array}{c}\text { Non-linear } \\
\text { programming }\end{array}$ & $\begin{array}{l}\text { Optimistic } \\
\text { view }\end{array}$ & - \\
\hline Shabanpour et al. [57] & Cooperative & One-stage & - & - & $\begin{array}{c}\text { Linear } \\
\text { programming }\end{array}$ & $\begin{array}{l}\text { Double- } \\
\text { frontier }\end{array}$ & - \\
\hline Badiezadeh et al. [42] & Cooperative & Three-stage & $\checkmark$ & $\checkmark$ & $\begin{array}{c}\text { Linear } \\
\text { programming }\end{array}$ & $\begin{array}{l}\text { Double- } \\
\text { frontier }\end{array}$ & - \\
\hline Current paper & Non-cooperative & Three-stage & $\checkmark$ & $\checkmark$ & $\begin{array}{c}\text { Non-linear } \\
\text { programming }\end{array}$ & $\begin{array}{l}\text { Double- } \\
\text { frontier }\end{array}$ & $\checkmark$ \\
\hline
\end{tabular}

Accordingly, three categories of sustainability factors (social, economic, and environmental) are presented in the literature. Determining sustainability goals requires the knowledge and a deeper understanding of the current level of sustainability. This can be achieved through sustainability assessments by taking into account all the three factors of sustainability including "economic, social, and environmental" [50]. Since the evaluation of a system involves a wide range of economic, social, and environmental indicators, it leads to complex multi-criteria decision-making problems. A possible way to simplify the assessment is to define the concept of sustainability and determine the importance of economic, social, and environmental indicators [51]. Extensive research has been conducted on the methods and applications of DEA; however, these efforts have focused mainly on assessing DMUs in the domain of engineering. More recently, researchers have employed the DEA to evaluate system performance considering sustainability factors. However, many of these studies cover only environmental and economic aspects, but social dimension is neglected as a dimension of sus- tainability $[52,53]$. Table 1 reviews the studies that have applied the game-theoretic methods in DEA. The last row of Table 1 presents the characteristics of the current study.

DEA is proposed as a theoretical framework for performance analysis, but its application to the healthcare setting remains quite scant. By and large, the contributions of this research are given below:

- A three-stage network is taken under consideration regarding additional desirable and undesirable inputs and outputs;

- An MDL with three levels (pre-test, test, and posttest) was simulated that allowed obtaining important information about the causes of inefficiency and efficiency of laboratory units;

- Sustainability criteria (economic, social, and environmental) are considered to measure the performance of MDLs, thus helping improve the social, economic, and environmental problems of laboratories; 


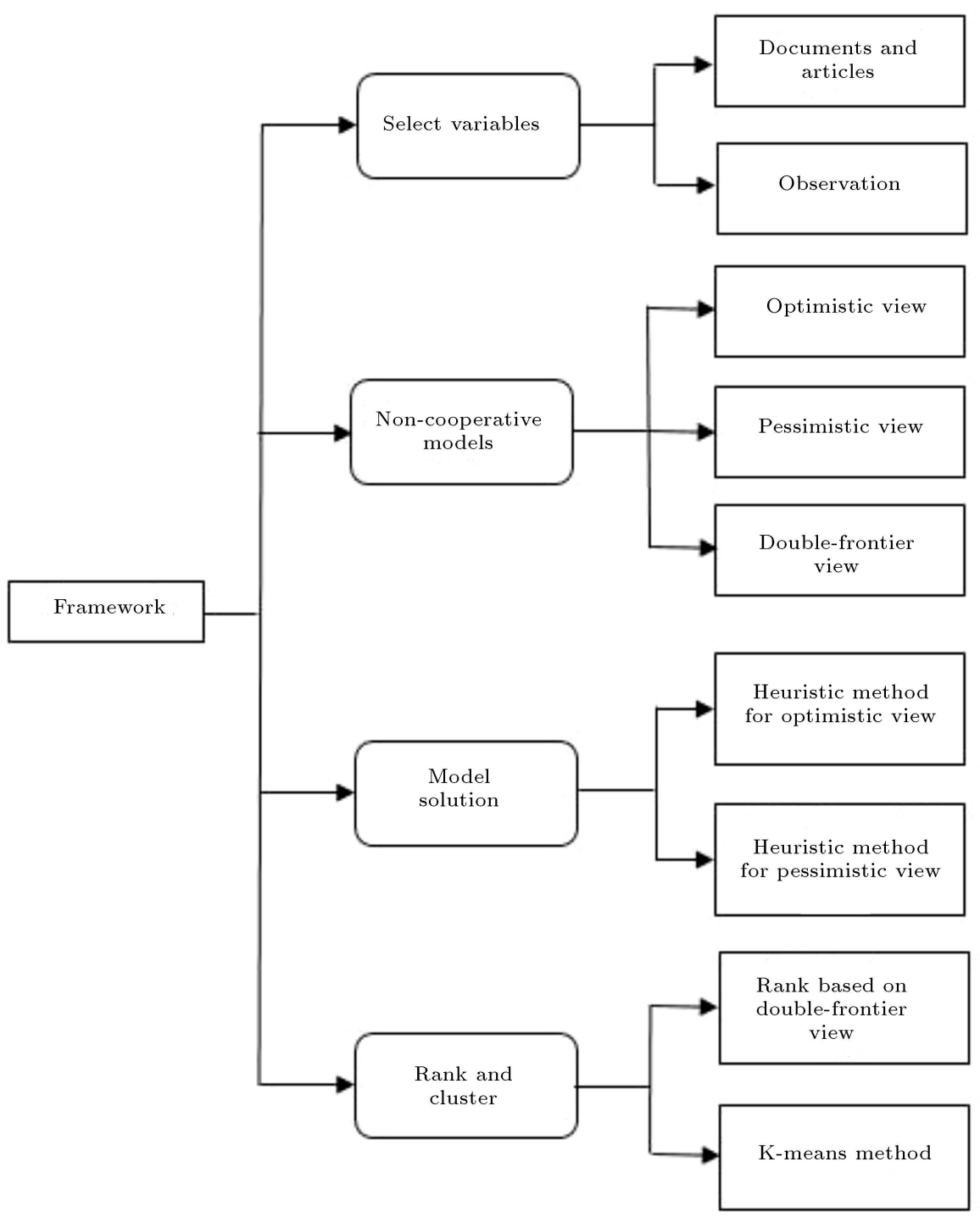

Figure 1. The research methodology.

- The criteria for evaluation are determined by utilizing the method of Fuzzy Delphi;

- A Double-Frontier Approach is utilized to evaluate efficiency to make results more realistic;

- $\mathrm{k}$-means algorithm based on the double-frontier view is suggested to determine the efficient and inefficient points of the network;

- A heuristic technique is suggested to turn nonlinear models into linear ones;

- The suggested model is applied to an authentic example.

\section{Methodology}

The adopted methodology is developed in four parts. In the first part, the data and variables are gathered. To this end, interviews and observation obtained by Fuzzy Delphi technique were compiled in line with library studies. Second, a NDEA method is presented to evaluate the efficiency of units from the doublefrontier viewpoint. In the third part, a heuristic method is suggested to turn nonlinear models into linear ones. Finally, k-means algorithm based on the double-frontier view is suggested to determine the efficient and inefficient points of the network. Figure 1 depicts the application of the proposed methodology.

\subsection{Identification of indicators}

Variables are not identified and there is no framework for guidance. Therefore, the criteria for evaluation are achieved by analyzing organizational documents (articles and library studies) and observations (interviews). Then, for screening the findings of this stage, experts' opinions and Fuzzy Delphi technique are used to achieve consensus about the influential criteria. In the case of Fuzzy Delphi technique, proper information about the criteria was obtained from the 
Table 2. Triangular fuzzy numbers of variables.

\begin{tabular}{lcc}
\hline $\begin{array}{c}\text { Linguistic } \\
\text { variables }\end{array}$ & $\begin{array}{c}\text { Triangular } \\
\text { fuzzy number }\end{array}$ & $\begin{array}{c}\text { Defuzzification } \\
\text { value }\end{array}$ \\
\hline Very low & $(0,0,0.25)$ & 0.0625 \\
Low & $(0.25,0.15,0.15)$ & 0.25 \\
Medium & $(0.5,0.25,0.25)$ & 0.5 \\
High & $(0.75,0.15,0.15)$ & 0.75 \\
Very high & $(1,0.25,0)$ & 0.9375 \\
\hline
\end{tabular}

experts in a written form and then, evaluated by a Fuzzy technique. The questionnaire was formed and distributed to gather experts' opinions about the extent of their agreement on the model criteria. Therefore, experts have stated their agreement by verbal variables (very high, high, medium, low, and very low). These variables are shown by Table 2 .

A triangular fuzzy number is denoted by $M=$ $(m, \alpha, \beta)$. $m$ represents the mean value, $\alpha$ the left- hand side of $M$, and $\beta$ the right-hand side of $M$. The defuzzification values are calculated based on Minkowski's formula in Table 2 as follows:

$$
x=m+\frac{\beta-\alpha}{4} .
$$

First, two approaches of observation and documentation are employed to determine the most significant indicators in the MDL domain. Proper indicators are given in Table 3 .

In the following, the effective criteria associated with the three MDL processes (pre-test, test, and posttest) are determined using the Fuzzy Delphi technique. The conceptual model along with the descriptions of the criteria is given to the expert members. In the following, the extent of their agreement on criteria is taken. Given the presented options and the linguistic variables defined in the questionnaire, the results are given in Table 4. The fuzzy mean of each criterion is calculated by Eqs. (2) and (3). In Eqs. (2) and (3), $A_{i}$

Table 3. Indicators effective in evaluating the efficiency of MDLs.

\begin{tabular}{|c|c|c|c|c|c|c|c|}
\hline Row & Indicator & Observation & $\begin{array}{c}\text { Leleu } \\
\text { et al. } \\
{[58]} \\
\end{array}$ & $\begin{array}{c}\text { Asandului } \\
\text { et al. } \\
{[59]}\end{array}$ & $\begin{array}{c}\text { Hamid Abu Bakar } \\
\text { et al. } \\
{[60]} \\
\end{array}$ & $\begin{array}{c}\text { Yousefi } \\
\text { et al. } \\
{[56]}\end{array}$ & $\begin{array}{c}\text { Patra } \\
\text { and Ray } \\
{[61]} \\
\end{array}$ \\
\hline 1 & Available space for service & $\checkmark$ & & & & & \\
\hline 2 & Average sample transfer time & & & & $\checkmark$ & & \\
\hline 3 & $\begin{array}{l}\text { Average waiting time for } \\
\text { sampling }\end{array}$ & $\checkmark$ & & & & & \\
\hline 4 & Correct number of tests & $\checkmark$ & & & & & \\
\hline 5 & Cost of consumables & & & & & $\checkmark$ & \\
\hline 6 & $\begin{array}{l}\text { Cost of laboratory space } \\
\text { and land value }\end{array}$ & $\checkmark$ & $\checkmark$ & & & & \\
\hline 7 & Cost of staff welfare & $\checkmark$ & & & & & \\
\hline 8 & Garbage weight & & & & & $\checkmark$ & \\
\hline 9 & Income from admission & $\checkmark$ & & & & & \\
\hline 10 & Lab profit & $\checkmark$ & & & & & \\
\hline 11 & Number of active experiments & $\checkmark$ & & & & & \\
\hline 12 & Number of false tests & $\checkmark$ & & $\checkmark$ & & & \\
\hline 13 & Number of kits & $\checkmark$ & & & & & \\
\hline 14 & Number of patients admitted & & $\checkmark$ & $\checkmark$ & & & $\checkmark$ \\
\hline 15 & $\begin{array}{l}\text { Number of responses of the } \\
\text { prepared tests }\end{array}$ & $\checkmark$ & & & & & \\
\hline 16 & Number of samples & $\checkmark$ & & & & & \\
\hline 17 & Safety cost of sampling unit & & & & & $\checkmark$ & \\
\hline 18 & Safety cost of test unit & & & & & $\checkmark$ & \\
\hline 19 & Staff wage & $\checkmark$ & & & & & \\
\hline 20 & $\begin{array}{l}\text { Sum of the scores of the } \\
\text { laboratory standards }\end{array}$ & $\checkmark$ & & & & & \\
\hline 21 & Test response time & $\checkmark$ & & & & & \\
\hline
\end{tabular}


Table 4. The average expert opinions in the first round.

\begin{tabular}{|c|c|c|c|}
\hline Row & Indicator & $\begin{array}{c}\text { Triangular } \\
\text { fuzzy average }\end{array}$ & $\begin{array}{c}\text { Defuzzification } \\
\text { value average } \\
(x)\end{array}$ \\
\hline 1 & Available space for service & $\left(\begin{array}{lll}0.54 & 0.79 & 0.96\end{array}\right)$ & 0.58 \\
\hline 2 & Average sample transfer time & $\left(\begin{array}{lll}0.54 & 0.77 & 0.97\end{array}\right)$ & 0.59 \\
\hline 3 & Average waiting time for sampling & $\left(\begin{array}{lll}0.56 & 0.79 & 0.97\end{array}\right)$ & 0.6 \\
\hline 4 & Correct number of tests & $\left(\begin{array}{llll}0.49 & 0.74 & 0.89\end{array}\right)$ & 0.52 \\
\hline 5 & Cost of consumables & $\left(\begin{array}{lll}0.59 & 0.84 & 0.96\end{array}\right)$ & 0.62 \\
\hline 6 & Cost of laboratory space and land value & $\left(\begin{array}{llll}0.06 & 0.29 & 0.54\end{array}\right)$ & 0.12 \\
\hline 7 & Cost of staff welfare & $\left(\begin{array}{lll}0.09 & 0.24 & 0.49\end{array}\right)$ & 0.15 \\
\hline 8 & Garbage weight & $\left(\begin{array}{lll}0.61 & 0.86 & 0.96\end{array}\right)$ & 0.64 \\
\hline 9 & Income from admission & $\left(\begin{array}{lll}0.57 & 0.84 & 0.96\end{array}\right)$ & 0.61 \\
\hline 10 & Lab profit & $\left(\begin{array}{lll}0.37 & 0.64 & 0.89\end{array}\right)$ & 0.43 \\
\hline 11 & Number of active experiments & $\left(\begin{array}{lll}0.46 & 0.71 & 0.91\end{array}\right)$ & 0.51 \\
\hline 12 & Number of false tests & $\left(\begin{array}{llll}0.51 & 0.74 & 0.89\end{array}\right)$ & 0.55 \\
\hline 13 & Number of kits & $\left(\begin{array}{lll}0.59 & 0.84 & 0.96\end{array}\right)$ & 0.62 \\
\hline 14 & Number of patients admitted & $\left(\begin{array}{lll}0.39 & 0.64 & 0.82\end{array}\right)$ & 0.43 \\
\hline 15 & Number of samples & $\left(\begin{array}{lll}0.69 & 0.86 & 0.99\end{array}\right)$ & 0.72 \\
\hline 16 & Responses of the prepared tests & $\left(\begin{array}{lll}0.31 & 0.54 & 0.77\end{array}\right)$ & 0.37 \\
\hline 17 & Safety cost of sampling unit & $\left(\begin{array}{lll}0.69 & 0.86 & 0.99\end{array}\right)$ & 0.72 \\
\hline 18 & Safety cost of test unit & $\left(\begin{array}{lll}0.46 & 0.39 & 0.64\end{array}\right)$ & 0.52 \\
\hline 19 & Staff wage & $\left(\begin{array}{lll}0.64 & 0.92 & 0.97\end{array}\right)$ & 0.7 \\
\hline 20 & Sum of the scores of the laboratory standards & $\left(\begin{array}{lll}0.64 & 0.89 & 0.99\end{array}\right)$ & 0.66 \\
\hline 21 & Test response time & $\left(\begin{array}{lll}0.64 & 0.89 & 0.99\end{array}\right)$ & 0.66 \\
\hline
\end{tabular}

and $A_{\text {ave }}$ represent the expert opinion $i$ and the average of expert opinion, respectively. Also, $n$ represents the number of experts.

$$
\begin{aligned}
A_{i}= & \left(a_{1}^{(i)}, a_{2}^{(i)}, a_{3}^{(i)}\right), \quad i=1,2, \cdots, n, \\
A_{\text {ave }} & =(m, \alpha, \beta) \\
& =\left(\frac{1}{n} \sum_{i=1}^{n} a_{1}^{(i)}, \frac{1}{n} \sum_{i=1}^{n} a_{2}^{(i)}, \frac{1}{n} \sum_{i=1}^{n} a_{3}^{(i)}\right) .
\end{aligned}
$$

As shown in Table 4, defuzzification operations and the triangular fuzzy average are calculated through Eqs. (3) and (1), respectively. According to the findings of Cheng and Lin [62], if the difference between the first and second rounds is lower than the very low threshold (0.1), consensus is achieved and the process is finished. Based on the polls of the second round, a new questionnaire is designed. In line with the former viewpoint of specialists and the obvious differences of the expert opinions all, the questionnaires are distributed among the expert members. Also, the members of the specialist group responded to the design questions again according to the opinions of other group members. The results are shown in Table 5 .

In the last column of Table 5 , members of the expert group share agreement on total criteria, except "available pace for service, number of false tests, and waste weight", because the difference between the first and second rounds is lower than the very low threshold (0.1). Therefore, we continued to make a survey on only three criteria. In the third round, a third questionnaire including three criteria was planned. According to the previous opinion of each specialist and the difference of all experts' opinions, the questionnaire was again given to the expert members. The fuzzy analysis of the results is shown in Table 6 .

Table 6 shows that the difference between the second and third rounds is lower than the threshold of 'very low' (0.1). According to the findings of Cheng and Lin [62], the consensus stops in this round. In Table 5, the two criteria in the range of 'very low' to 'medium' effect are removed. The criteria including available space for service, average sample 
Table 5. The average expert opinions in the second round.

\begin{tabular}{|c|c|c|c|c|}
\hline Row & Indicator & $\begin{array}{c}\text { Triangular } \\
\text { fuzzy average }\end{array}$ & $\begin{array}{c}\text { Defuzzification } \\
\text { value average }\end{array}$ & $\begin{array}{l}\text { Difference of } \\
\text { the first and } \\
\text { second rounds }\end{array}$ \\
\hline 1 & Correct number of tests & $\left(\begin{array}{lll}0.49 & 0.59 & 0.77\end{array}\right)$ & 0.53 & 0.01 \\
\hline 2 & Average sample transfer time & $\left(\begin{array}{lll}0.57 & 0.72 & 0.94\end{array}\right)$ & 0.62 & 0.03 \\
\hline 3 & Test response time & $\left(\begin{array}{lll}0.67 & 0.74 & 0.89\end{array}\right)$ & 0.7 & 0.04 \\
\hline 4 & Cost of laboratory space and land value & $\left(\begin{array}{lll}0.11 & 0.17 & 0.42\end{array}\right)$ & 0.17 & 0.05 \\
\hline 5 & Number of samples & $\left(\begin{array}{lll}0.74 & 0.79 & 0.92\end{array}\right)$ & 0.77 & 0.05 \\
\hline 6 & Average waiting time for sampling & $\left(\begin{array}{lll}0.62 & 0.72 & 0.89\end{array}\right)$ & 0.66 & 0.06 \\
\hline 7 & Cost of staff welfare & $\left(\begin{array}{lll}0.15 & 0.19 & 0.44\end{array}\right)$ & 0.21 & 0.06 \\
\hline 8 & Safety cost of test unit & $\left(\begin{array}{lll}0.53 & 0.66 & 0.86\end{array}\right)$ & 0.58 & 0.06 \\
\hline 9 & Safety cost of sampling unit & $\left(\begin{array}{lll}0.75 & 0.81 & 0.94\end{array}\right)$ & 0.78 & 0.06 \\
\hline 10 & Responses of the prepared tests & $\left(\begin{array}{lll}0.39 & 0.54 & 0.76\end{array}\right)$ & 0.44 & 0.07 \\
\hline 11 & Cost of consumables & $\left(\begin{array}{lll}0.65 & 0.73 & 0.88\end{array}\right)$ & 0.69 & 0.07 \\
\hline 12 & Lab profit & $\left(\begin{array}{lll}0.44 & 0.61 & 0.86\end{array}\right)$ & 0.5 & 0.07 \\
\hline 13 & Number of kits & $\left(\begin{array}{lll}0.66 & 0.76 & 0.94\end{array}\right)$ & 0.7 & 0.08 \\
\hline 14 & Sum of the scores of the laboratory standards & $\left(\begin{array}{lll}0.71 & 0.79 & 0.94\end{array}\right)$ & 0.75 & 0.09 \\
\hline 15 & Number of patients admitted & $\left(\begin{array}{lll}0.47 & 0.62 & 0.84\end{array}\right)$ & 0.52 & 0.09 \\
\hline 16 & Number of active experiments & $\left(\begin{array}{lll}0.54 & 0.71 & 0.96\end{array}\right)$ & 0.6 & 0.09 \\
\hline 17 & Staff wage & $\left(\begin{array}{lll}0.76 & 0.79 & 0.89\end{array}\right)$ & 0.79 & 0.09 \\
\hline 18 & Income from admission & $\left(\begin{array}{llll}0.66 & 0.74 & 0.89\end{array}\right)$ & 0.7 & 0.09 \\
\hline 19 & Available space for service & $\left(\begin{array}{lll}0.66 & 0.74 & 0.96\end{array}\right)$ & 0.72 & 0.14 \\
\hline 20 & Garbage weight & $\left(\begin{array}{lll}0.78 & 0.84 & 0.96\end{array}\right)$ & 0.81 & 0.17 \\
\hline 21 & Number of false tests & $\left(\begin{array}{lll}0.70 & 0.79 & 0.94\end{array}\right)$ & 0.74 & 0.19 \\
\hline
\end{tabular}

Table 6. The average expert opinions in the third round.

\begin{tabular}{|c|c|c|c|c|}
\hline Row & Indicator & $\begin{array}{c}\text { Triangular } \\
\text { fuzzy average }\end{array}$ & $\begin{array}{c}\text { Defuzzification } \\
\text { value average } \\
(x)\end{array}$ & $\begin{array}{c}\text { Difference of } \\
\text { the second and } \\
\text { third rounds }\end{array}$ \\
\hline 1 & Number of false tests & $\left(\begin{array}{lll}0.64 & 0.89 & 1.09\end{array}\right)$ & 0.69 & 0.05 \\
\hline 2 & Garbage weight & $\left(\begin{array}{llll}0.69 & 0.96 & 1.11\end{array}\right)$ & 0.73 & 0.08 \\
\hline 3 & Available space for service & $\left(\begin{array}{llll}0.56 & 0.79 & 1.07\end{array}\right)$ & 0.63 & 0.09 \\
\hline
\end{tabular}

transfer time, average waiting time for sampling, cost of consumables, garbage weight, income from admission, number of active experiments, number of false tests, number of kits, safety cost of sampling unit and safety cost of test unit, staff wage, sum of the scores of the laboratory standards, and test response time are in the range of 'very high' effect to 'high' effect. Other criteria including correct number of tests, lab profit, number of admitted patients, and number of replies to the prepared tests are in the range of 'medium' effect. Out of twenty-one effective criteria of MDLs in the two rounds of polls conducted, eighteen executable criteria were specified in the area of MDLs upon removing three criteria of "cost of laboratory space, land value, and cost of staff welfare". Table 7 shows effective final indicators for measuring the efficiency of MDLs using Fuzzy Delphi technique.

\subsection{Model description}

This study investigates a set of $n$ homogeneous DMUs shown by $D M U_{j}(j=1,2, \cdots, n)$, and each $D M U_{j}$ has three stages with a complex internal structure, as shown in Figure 2. We define the desirable and undesirable inputs and outputs of the first stage by $x_{i_{1} j}\left(i_{1}=1,2, \cdots, I_{1}\right), x_{i_{2} j}\left(i_{2}=1,2, \cdots, I_{2}\right), y_{r_{1} j}$ $\left(r_{1}=1,2, \cdots, R_{1}\right)$, and $y_{r_{2} j}\left(r_{2}=1,2, \cdots, R_{2}\right)$, respectively. We define the intermediate measures between the stages by $z_{d_{1} j}\left(d_{1}=1,2, \cdots, D_{1}\right)$ and $z_{d_{2} j}$ $\left(d_{2}=1,2, \cdots, D_{2}\right)$. The additional desirable inputs and undesirable outputs of the second stage are defined 
Table 7. Effective indicators for the efficiency evaluation of MDLs.

\begin{tabular}{clcl}
\hline Row & \multicolumn{1}{c}{ Indicator } & Row & \multicolumn{1}{c}{ Indicator } \\
\hline 1 & Available space for service & 11 & Number of kits \\
2 & Average sample transfer time & 12 & Number of patients admitted \\
3 & Average waiting time for sampling & 13 & Number of samples \\
4 & Correct number of tests & 14 & Responses of the prepared tests \\
5 & Cost of consumables & 15 & Safety cost of sampling unit \\
6 & Garbage weight & 16 & Safety cost of test unit \\
7 & Income from admission & 17 & Staff wage \\
8 & Lab profit & 18 & Sum of the scores of the laboratory standards \\
9 & Number of active experiments & 19 & Test response time \\
10 & Number of false tests & & \\
\hline
\end{tabular}

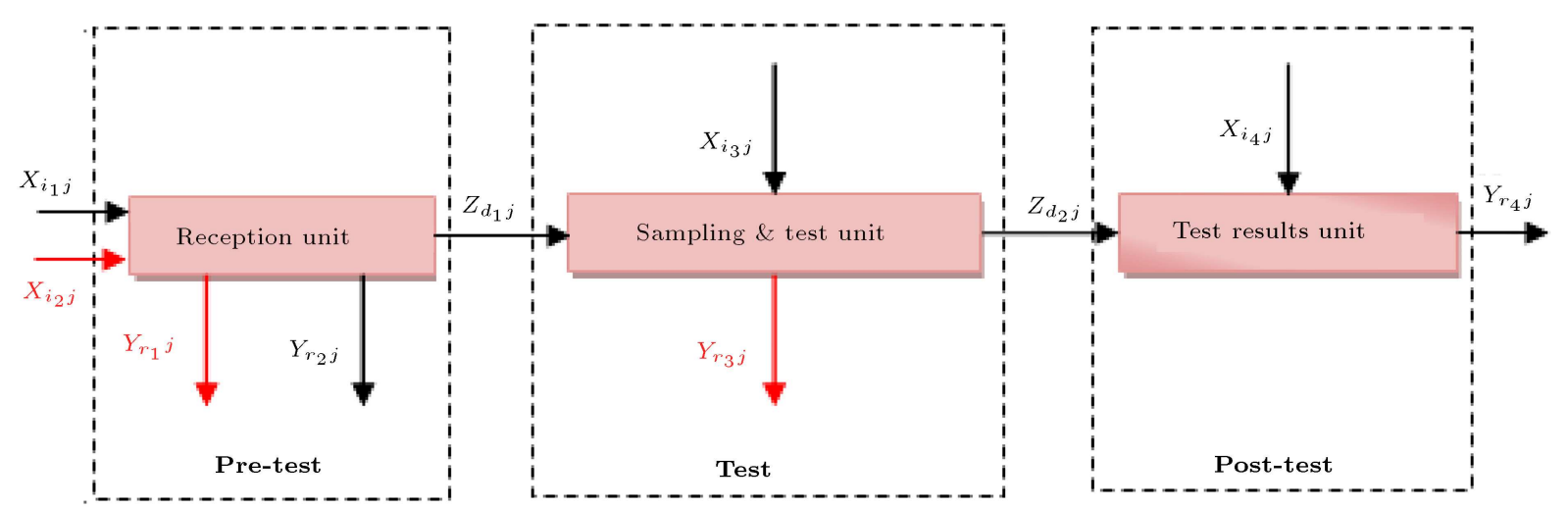

Figure 2. The structure of the three-stage network system with additional inputs and undesirable outputs.

by $x_{i_{3} j}\left(i_{3}=1,2, \cdots, I_{3}\right)$ and $y_{r_{3} j}\left(r_{3}=1,2, \cdots, R_{3}\right)$, respectively. Finally, the additional desirable inputs and desirable outputs of the third stage are defined by $x_{i_{4} j}\left(i_{4}=1,2, \cdots, I_{4}\right)$ and $y_{r_{4} j}\left(r_{4}=1,2, \cdots, R_{4}\right)$. Kao and Hwang [16] used uniform weights for the intermediate variables to evaluate the efficiency of the network. Therefore, we utilized similar weights for the intermediate variables in the models. $v_{i_{1}}, v_{i_{2}}, v_{i_{3}}$, and $v_{i_{4}}$ are denoted by the weights of the inputs to the first, second, and third stages, respectively. The weights of the intermediate measures between the stages are denoted by $\eta_{d_{1}}$ and $\eta_{d_{2}}$. The weights of the outputs for the first, second, and third stages are defined by $u_{r_{1}}$, $u_{r_{2}}, u_{r_{3}}$, and $u_{r_{4}}$, respectively.

Researchers are likely to use input-oriented models in efficiency analysis for three major reasons. First, demand is on the rise and estimating it is an intricate matter. Second, managers have greater control over inputs than outputs. Third, this model reflects the primary goals of policymakers responsible for responding to the requirements of people and that the units must reduce costs or else, limit the use of resources. Thereby, this research utilizes the inputoriented model. In accordance with Korhonen and Luptacik [63], we signify the undesirable output in the models as a desirable output by a negative mark.
Also, the undesirable input is considered as a desirable input with a negative mark. Based on the opinions of managers, we will assign the first stage (reception unit), the second stage (sampling and testing unit), and the third stage (test results unit) to the roles of the "leader", "first follower", and "second follower", respectively. Hence, the optimistic and pessimistic efficiencies of the leader's stage are denoted by $\theta_{o}^{L}$ and $\varphi_{o}^{L}$, respectively; the optimistic and pessimistic efficiencies of the second and third stages are $\theta_{o}^{1 F}, \theta_{o}^{2 F}$ and $\varphi_{o}^{1 F}, \varphi_{o}^{2 F}$, respectively. Based on the managers' ideas, the first stage is depicted as the leader, while the second and third stages together as the follower. On these bases, the optimistic and pessimistic efficiencies of the second and third stages together are defined as $\theta_{o}^{12 F}$ and $\varphi_{o}^{12 F}$, respectively. We define the maximal efficiency of the leader stage on the bases of Liang et al. [29] approach from an optimistic point of view as hereunder:

\section{Model 1}

$$
\theta_{o}^{L *}=\max \frac{\sum_{d_{1}=1}^{D_{1}} \eta_{d_{1}} z_{d_{1} o}+\sum_{r_{2}=1}^{R_{2}} u_{r_{2}} y_{r_{2} o}-\sum_{r_{1}=1}^{R_{1}} u_{r_{1}} y_{r_{1} o}}{\sum_{i_{1}=1}^{I_{1}} v_{i_{1}} x_{i_{1} o}-\sum_{i_{2}=1}^{I_{2}} v_{i_{2}} x_{i_{2} o}},
$$


s.t.:

$$
\left.\begin{array}{l}
\frac{\sum_{d_{1}=1}^{D_{1}} \eta_{d_{1}} z_{d_{1} j}+\sum_{r_{2}=1}^{R_{2}} u_{r_{2}} y_{r_{2} j}-\sum_{r_{1}=1}^{R_{1}} u_{r_{1}} y_{r_{1} j}}{\sum_{i_{1}=1}^{I_{1}} v_{i_{1}} x_{i_{1} j}-\sum_{i_{2}=1}^{I_{2}} v_{i_{2}} x_{i_{2} j}} \leqslant 1, \\
j=1, \cdots, n, \\
\sum_{d_{2}=1}^{D_{2}} \eta_{d_{2}} z_{d_{2} j}-\sum_{r_{3}=1}^{R_{3}} u_{r_{3}} y_{r_{3} j} \\
\sum_{i_{3}=1}^{I_{3}} v_{i_{3}} x_{i_{3} j}+\sum_{d_{1}=1}^{D_{1}} \eta_{d_{1}} z_{d_{1} j} \\
\sum_{r_{4}=1}^{R_{4}} u_{r_{4}} y_{r_{4} j} \\
\sum_{i_{4}=1}^{I_{4}} v_{i_{4}} x_{i_{4} j}+\sum_{d_{2}=1}^{D_{2}} \eta_{d_{2}} z_{d_{2} j} \\
\eta_{d_{1}}, \eta_{d_{2}}, u_{r_{1}}, u_{r_{2}}, u_{r_{3}}, u_{r_{4}}, v_{i_{1}}, v_{i_{2}}, v_{i_{3}}, v_{i_{4}} \geqslant \varepsilon ;
\end{array}\right\}
$$

The optimum efficiency is indicated by symbol $\left(^{*}\right)$ in Model 1. Through Model 1, the maximal efficiency of the leader's stage $\left(\theta_{o}^{L *}\right)$ was attained on conditions that none of the efficiencies of the other stages $\left(\theta_{j}^{L}, \theta_{j}^{1 F}, \theta_{j}^{2 F}\right)$ would be more than (1) or $\theta_{o}^{L *}=\max \left\{\theta_{o}^{L} \mid \theta_{j}^{L} \leq\right.$ $\left.1, \theta_{j}^{1 F} \leq 1, \theta_{j}^{2 F} \leq 1, j=1, \cdots, n\right\}$. Model 1 is fractional and is converted into linear models through the Charnes-Cooper conversion [64], as illustrated below. Let:

$$
T=\frac{1}{\sum_{i_{1}=1}^{I_{1}} v_{i_{1}} x_{i_{1} o}-\sum_{i_{2}=1}^{I_{2}} v_{i_{2}} x_{i_{2} o}} .
$$

Thus, we have Model 2.

\section{Model 2}

$$
\theta_{o}^{L *}=\max \sum_{d_{1}=1}^{D_{1}} \eta_{d_{1}} z_{d_{1} o}+\sum_{r_{2}=1}^{R_{2}} u_{r_{2}} y_{r_{2} o}-\sum_{r_{1}=1}^{R_{1}} u_{r_{1}} y_{r_{1} o}
$$

s.t.:

$$
\sum_{i_{1}=1}^{I_{1}} v_{i_{1}} x_{i_{1} o}-\sum_{i_{2}=1}^{I_{2}} v_{i_{2}} x_{i_{2} o}=1
$$

$$
\begin{aligned}
& \sum_{d_{1}=1}^{D_{1}} \eta_{d_{1}} z_{d_{1} j}+\sum_{r_{2}=1}^{R_{2}} u_{r_{2}} y_{r_{2} j}-\sum_{r_{1}=1}^{R_{1}} u_{r_{1}} y_{r_{1} j} \\
& -\left(\sum_{i_{1}=1}^{I_{1}} v_{i_{1}} x_{i_{1} j}-\sum_{i_{2}=1}^{I_{2}} v_{i_{2}} x_{i_{2} j}\right) \leq 0 \\
& j=1, \cdots, n, \\
& \sum_{d_{2}=1}^{D_{2}} \eta_{d_{2}} z_{d_{2} j}-\sum_{r_{3}=1}^{R_{3}} u_{r_{3}} y_{r_{3} j} \\
& -\left(\sum_{i_{3}=1}^{I_{3}} v_{i_{3}} x_{i_{3}} j+\sum_{d_{1}=1}^{D_{1}} \eta_{d_{1}} z_{d_{1} j}\right) \leq 0 \\
& j=1, \cdots, n, \\
& \sum_{r_{4}=1}^{R_{4}} u_{r_{4}} y_{r_{4} j}-\left(\sum_{i_{4}=1}^{I_{4}} v_{i_{4}} x_{i_{4} j}+\sum_{d_{2}=1}^{D_{2}} \eta_{d_{2}} z_{d_{2} j}\right) \leq 0 \\
& j=1, \cdots, n, \\
& \eta_{d_{1}}, \eta_{d_{2}}, u_{r_{1}}, u_{r_{2}}, u_{r_{3}}, u_{r_{4}}, v_{i_{1}}, v_{i_{2}}, v_{i_{3}}, v_{i_{4}} \geq \varepsilon \\
& d_{1}=1,2, \cdots, D_{1} ; \quad d_{2}=1,2, \cdots, D_{2} ; \\
& r_{1}=1,2, \cdots, R_{1} ; \quad r_{2}=1,2, \cdots, R_{2} ; \\
& r_{3}=1,2, \cdots, R_{3} ; \quad r_{4}=1,2, \cdots, R_{4} ; \\
& i_{1}=1,2, \cdots, I_{1} ; \quad i_{2}=1,2, \cdots, I_{2} ; \\
& i_{3}=1,2, \cdots, I_{3} ; \quad i_{4}=1,2, \cdots, I_{4} .
\end{aligned}
$$

We, based on the tasks of Wang et al. [65], have modified Model 2 and defined the efficiency of the leader stage from the pessimistic view according to the following:

\section{Model 3}

$\varphi_{o}^{L *}=\min \sum_{d_{1}=1}^{D_{1}} \eta_{d_{1}} z_{d_{1} o}+\sum_{r_{2}=1}^{R_{2}} u_{r_{2}} y_{r_{2} o}-\sum_{r_{1}=1}^{R_{1}} u_{r_{1}} y_{r_{1} o}$,

s.t.

$$
\begin{aligned}
& \sum_{i_{1}=1}^{I_{1}} v_{i_{1}} x_{i_{1} o}-\sum_{i_{2}=1}^{I_{2}} v_{i_{2}} x_{i_{2} o}=1 \\
& \sum_{d_{1}=1}^{D_{1}} \eta_{d_{1}} z_{d_{1} j}+\sum_{r_{2}=1}^{R_{2}} u_{r_{2}} y_{r_{2} j}-\sum_{r_{1}=1}^{R_{1}} u_{r_{1}} y_{r_{1} j} \\
& \quad-\left(\sum_{i_{1}=1}^{I_{1}} v_{i_{1}} x_{i_{1} j}-\sum_{i_{2}=1}^{I_{2}} v_{i_{2}} x_{i_{2} j}\right) \geq 0
\end{aligned}
$$




$$
\begin{aligned}
& j=1, \cdots, n, \\
& \sum_{d_{2}=1}^{D_{2}} \eta_{d_{2}} z_{d_{2} j}-\sum_{r_{3}=1}^{R_{3}} u_{r_{3}} y_{r_{3} j} \\
& -\left(\sum_{i_{3}=1}^{I_{3}} v_{i_{3}} x_{i_{3} j}+\sum_{d_{1}=1}^{D_{1}} \eta_{d_{1}} z_{d_{1} j}\right) \geq 0 \\
& j=1, \cdots, n, \\
& \sum_{r_{4}=1}^{R_{4}} u_{r_{4}} y_{r_{4} j}-\left(\sum_{i_{4}=1}^{I_{4}} v_{i_{4}} x_{i_{4} j}+\sum_{d_{2}=1}^{D_{2}} \eta_{d_{2}} z_{d_{2} j}\right) \geq 0 \\
& j=1, \cdots, n, \\
& \eta_{d_{1}}, \eta_{d_{2}}, u_{r_{1}}, u_{r_{2}}, u_{r_{3}}, u_{r_{4}}, v_{i_{1}}, v_{i_{2}}, v_{i_{3}}, v_{i_{4}} \geq \varepsilon \\
& d_{1}=1,2, \cdots, D_{1} ; \quad d_{2}=1,2, \cdots, D_{2} ; \\
& r_{1}=1,2, \cdots, R_{1} ; \quad r_{2}=1,2, \cdots, R_{2} ; \\
& r_{3}=1,2, \cdots, R_{3} ; \quad r_{4}=1,2, \cdots, R_{4} ; \\
& i_{1}=1,2, \cdots, I_{1} ; \quad i_{2}=1,2, \cdots, I_{2} ; \\
& i_{3}=1,2, \cdots, I_{3} ; \quad i_{4}=1,2, \cdots, I_{4} .
\end{aligned}
$$

The maximal optimistic and minimal pessimistic efficiencies of the leader stage $\left(\theta_{o}^{L *}\right.$ and $\left.\varphi_{o}^{L *}\right)$ are obtained from Models 2 and 3 , respectively. To calculate the efficiency of the followers, we will consider the second and third stages as one stage and gain the efficiency of the follower stage. Kao and Hwang [16] used a multiplicative approach to measure the overall efficiency of a series structure. Then, the efficiencies of the second and third stages of a system, as shown in Figure 2, are defined from the optimistic view as $\theta_{o}^{12 F}=\theta_{o}^{1 F} \cdot \theta_{o}^{2 F}$. Thus, we have Model 4 .

\section{Model 4}

$$
\begin{gathered}
\theta_{o}^{12 F}=\max \frac{\sum_{d_{2}=1}^{D_{2}} \eta_{d_{2}} z_{d_{2} o}-\sum_{r_{3}=1}^{R_{3}} u_{r_{3}} y_{r_{3} o}}{\sum_{i_{3}=1}^{I_{3}} v_{i_{3}} x_{i_{3} o}+\sum_{d_{1}=1}^{D_{1}} \eta_{d_{1}} z_{d_{1} o}} \\
\cdot \frac{\sum_{r_{4}=1}^{R_{4}} u_{r_{4}} y_{r_{4} o}}{\sum_{i_{4}=1}^{I_{4}} v_{i_{4}} x_{i_{4} o}+\sum_{d_{2}=1}^{D_{2}} \eta_{d_{2}} z_{d_{2} o}}
\end{gathered}
$$

$$
\begin{aligned}
& \frac{\sum_{d_{1}=1}^{D_{1}} \eta_{d_{1}} z_{d_{1} j}+\sum_{r_{2}=1}^{R_{2}} u_{r_{2}} y_{r_{2} j}-\sum_{r_{1}=1}^{R_{1}} u_{r_{1}} y_{r_{1} j}}{\sum_{i_{1}=1}^{I_{1}} v_{i_{1}} x_{i_{1} j}-\sum_{i_{2}=1}^{I_{2}} v_{i_{2}} x_{i_{2} j}} \leq 1 \\
& j=1, \cdots, n, \\
& \frac{\sum_{d_{2}=1}^{D_{2}} \eta_{d_{2}} z_{d_{2} j}-\sum_{r_{3}=1}^{R_{3}} u_{r_{3}} y_{r_{3} j}}{\sum_{i_{3}=1}^{I_{3}} v_{i_{3}} x_{i_{3} j}+\sum_{d_{1}=1}^{D_{1}} \eta_{d_{1}} z_{d_{1} j}} \leqslant 1, \\
& j=1, \cdots, n, \\
& \frac{\sum_{r_{4}=1}^{R_{4}} u_{r_{4}} y_{r_{4} j}}{\sum_{i_{4}=1}^{I_{4}} v_{i_{4}} x_{i_{4} j}+\sum_{d_{2}=1}^{D_{2}} \eta_{d_{2}} z_{d_{2} j}} \leq 1 \\
& j=1, \cdots, n, \\
& \frac{\sum_{d_{1}=1}^{D_{1}} \eta_{d_{1}} z_{d_{1} o}+\sum_{r_{2}=1}^{R_{2}} u_{r_{2}} y_{r_{2} o}-\sum_{r_{1}=1}^{R_{1}} u_{r_{1}} y_{r_{1} o}}{\sum_{i_{1}=1}^{I_{1}} v_{i_{1}} x_{i_{1} o}-\sum_{i_{2}=1}^{I_{2}} v_{i_{2}} x_{i_{2} o}}=\theta_{o}^{L *}, \\
& \eta_{d_{1}}, \eta_{d_{2}}, u_{r_{1}}, u_{r_{2}}, u_{r_{3}}, u_{r_{4}}, v_{i_{1}}, v_{i_{2}}, v_{i_{3}}, v_{i_{4}} \geq \varepsilon \\
& d_{1}=1,2, \cdots, D_{1} ; \quad d_{2}=1,2, \cdots, D_{2} ; \\
& r_{1}=1,2, \cdots, R_{1} ; \quad r_{2}=1,2, \cdots, R_{2} ; \\
& r_{3}=1,2, \cdots, R_{3} ; \quad r_{4}=1,2, \cdots, R_{4} ; \\
& i_{1}=1,2, \cdots, I_{1} ; \quad i_{2}=1,2, \cdots, I_{2} ; \\
& i_{3}=1,2, \cdots, I_{3} ; \quad i_{4}=1,2, \cdots, I_{4} .
\end{aligned}
$$

Model 4 demonstrates the maximal overall efficiency of the second and third stages in Figure 2 and measures it from the optimistic view on conditions that the efficiency of all the stages be lower than (1) and in the case of the method of $\mathrm{Li}$ et al. [30], the efficiency of the leader's stage must remain constant. We, based on the tasks of Wang et al. [65], have modified Model 4 and defined the minimal efficiency of the overall follower stages from the pessimistic viewpoint according to the following:

\section{Model 5}

$$
\varphi_{o}^{12 F}=\min \frac{\sum_{d_{2}=1}^{D_{2}} \eta_{d_{2}} z_{d_{2} o}-\sum_{r_{3}=1}^{R_{3}} u_{r_{3}} y_{r_{3} o}}{\sum_{i_{3}=1}^{I_{3}} v_{i_{3}} x_{i_{3} o}+\sum_{d_{1}=1}^{D_{1}} \eta_{d_{1}} z_{d_{1} o}}
$$




$$
\frac{\sum_{r_{4}=1}^{R_{4}} u_{r_{4}} y_{r_{4} o}}{\sum_{i_{4}=1}^{I_{4}} v_{i_{4}} x_{i_{4} o}+\sum_{d_{2}=1}^{D_{2}} \eta_{d_{2}} z_{d_{2} o}}
$$

s.t.:

$$
\begin{aligned}
& \frac{\sum_{d_{1}=1}^{D_{1}} \eta_{d_{1}} z_{d_{1} j}+\sum_{r_{2}=1}^{R_{2}} u_{r_{2}} y_{r_{2} j}-\sum_{r_{1}=1}^{R_{1}} u_{r_{1}} y_{r_{1} j}}{\sum_{i_{1}=1}^{I_{1}} v_{i_{1}} x_{i_{1} j}-\sum_{i_{2}=1}^{I_{2}} v_{i_{2}} x_{i_{2} j}} \geq 1 \\
& j=1, \cdots, n, \\
& \frac{\sum_{d_{2}=1}^{D_{2}} \eta_{d_{2}} z_{d_{2} j}-\sum_{r_{3}=1}^{R_{3}} u_{r_{3}} y_{r_{3} j}}{\sum_{i_{3}=1}^{I_{3}} v_{i_{3}} x_{i_{3} j}+\sum_{d_{1}=1}^{D_{1}} \eta_{d_{1}} z_{d_{1} j}} \geq 1, \quad j=1, \cdots, n \\
& \frac{\sum_{r_{4}=1}^{R_{4}} u_{r_{4}} y_{r_{4} j}}{\sum_{i_{4}=1}^{I_{4}} v_{i_{4}} x_{i_{4} j}+\sum_{d_{2}=1}^{D_{2}} \eta_{d_{2}} z_{d_{2} j}} \geq 1, \quad j=1, \cdots, n, \\
& \frac{\sum_{d_{1}=1}^{D_{1}} \eta_{d_{1}} z_{d_{1} o}+\sum_{r_{2}=1}^{R_{2}} u_{r_{2}} y_{r_{2} o}-\sum_{r_{1}=1}^{R_{1}} u_{r_{1}} y_{r_{1} o}}{\sum_{i_{1}=1}^{I_{1}} v_{i_{1}} x_{i_{1} o}-\sum_{i_{2}=1}^{I_{2}} v_{i_{2}} x_{i_{2} o}}=\varphi_{o}^{L *}, \\
& \eta_{d_{1}}, \eta_{d_{2}}, u_{r_{1}}, u_{r_{2}}, u_{r_{3}}, u_{r_{4}}, v_{i_{1}}, v_{i_{2}}, v_{i_{3}}, v_{i_{4}} \geq \varepsilon \\
& d_{1}=1,2, \cdots, D_{1} ; \quad d_{2}=1,2, \cdots, D_{2} ; \\
& r_{1}=1,2, \cdots, R_{1} ; \quad r_{2}=1,2, \cdots, R_{2} ; \\
& r_{3}=1,2, \cdots, R_{3} ; \quad r_{4}=1,2, \cdots, R_{4} ; \\
& i_{1}=1,2, \cdots, I_{1} ; \quad i_{2}=1,2, \cdots, I_{2} ; \\
& i_{3}=1,2, \cdots, I_{3} ; \quad i_{4}=1,2, \cdots, I_{4} .
\end{aligned}
$$

Models 4 and 5 are nonlinear and an innovative method for resolving them is utilized in the fourth part of this research. Accordingly, Models 4 and 5 are resolved and we define the maximal optimistic efficiency and the minimal pessimistic efficiency of a network, as shown in Figure 2, in Eq. (4) as follows:

$$
\theta_{o}^{\text {overall }}{ }^{*}=\theta_{o}^{L *} \cdot \theta_{o}^{12 F *}, \quad \varphi_{o}^{\text {overall* }}=\varphi_{o}^{L *} \cdot \varphi_{o}^{12 F *} .
$$

Based on the tasks of Wang and Chin [39], the overall efficiency is defined according to the double- frontier in Eq. (5):

$$
\phi_{o}^{*}=\sqrt{\theta_{o}^{\text {overall }^{*} \cdot \varphi_{o}^{\text {overall }}} \text {. }} .
$$

Therefore, modeling of the network, as shown in Figure 2 , is performed based on the three approaches (the optimistic, pessimistic, and double-frontier). Next, the $\mathrm{k}$-means algorithm is utilized to cluster the DMUs into several groups based on the double-frontier view and these results are shown in the case study section.

\section{Model solution}

Two exploratory approaches are proposed for the optimistic and pessimistic views. It is for the first time that we have developed an exploratory approach in relevance to the pessimistic perspective or condition, which we, with the best of our findings, had failed to perform the modeling, similar to this conceptual approach under pessimistic conditions to date. Similarly, an exploratory approach has been implemented from the optimistic standpoint in relation to the leaderfollower concept. Thereby, the exploratory approach from the pessimistic angle is proposed in this paper. Models 4 and 5 cannot be converted into linear models because of the additional inputs and outputs in the stages. Thus, the heuristic approach given to solving Models 4 and 5 is proposed.

\subsection{A heuristic technique to solve the optimistic view}

The objective function of Model 4 is a product of multiplicative efficiency of the two stages. We consider $\theta_{o}^{1 F}$ as a variable in the objective function, which is between the $\left[0, \theta_{o}^{1 F-\max }\right]$ interval and change. $\theta_{o}^{1 F}$ is defined in the figure so that we can move it to the interval:

$$
\begin{aligned}
& \theta_{o}^{1 F}=\theta_{o}^{1 F-\max }-k_{1} \Delta \varepsilon, \\
& k_{1}=0,1, \cdots,\left[\frac{\theta_{o}^{1 F-\max }}{\Delta \varepsilon}\right]+1 .
\end{aligned}
$$

In Eq. (6), $\Delta \varepsilon$ represents a step size with a very small value and $\theta_{o}^{1 F-\max }$ is defined as the maximum optimistic efficiency of the first follower stage. From the following model, its value is capable of being computed.

\section{Model 6}

$$
\begin{gathered}
\theta_{o}^{1 F-\max }=\max \left\{\theta_{o}^{1 F} \mid \theta_{j}^{L} \leq 1, \theta_{j}^{1 F} \leq 1, \theta_{j}^{2 F} \leq 1,\right. \\
j=1, \cdots, n\} .
\end{gathered}
$$

All the variables are non-negative in Model 6. The aforementioned models have attained the maximum efficiency of the first follower stage on conditions that the efficiency of the stages be less than (1). This model is fractional and is converted into linear models through the Charnes-Cooper conversion [64] as follows: 


\section{Model 7}

$$
\theta_{o}^{1 F-\max *}=\max \sum_{d_{2}=1}^{D_{2}} \eta_{d_{2}} z_{d_{2} o}-\sum_{r_{3}=1}^{R_{3}} u_{r_{3}} y_{r_{3} o}
$$

s.t.:

$$
\begin{aligned}
& \sum_{i_{3}=1}^{I_{3}} v_{i_{3}} x_{i_{3} o}+\sum_{d_{1}=1}^{D_{1}} \eta_{d_{1}} z_{d_{1} o}=1 \\
& \sum_{d_{1}=1}^{D_{1}} \eta_{d_{1}} z_{d_{1} j}+\sum_{r_{2}=1}^{R_{2}} u_{r_{2}} y_{r_{2} j}-\sum_{r_{1}=1}^{R_{1}} u_{r_{1}} y_{r_{1} j} \\
& \quad-\left(\sum_{i_{1}=1}^{I_{1}} v_{i_{1}} x_{i_{1} j}-\sum_{i_{2}=1}^{I_{2}} v_{i_{2}} x_{i_{2} j}\right) \leq 0,
\end{aligned}
$$$$
j=1, \cdots, n,
$$$$
\begin{aligned}
\sum_{d_{2}=1}^{D_{2}} \eta_{d_{2}} z_{d_{2} j}-\sum_{r_{3}=1}^{R_{3}} u_{r_{3}} y_{r_{3} j} \\
-\left(\sum_{i_{3}=1}^{I_{3}} v_{i_{3}} x_{i_{3} j}+\sum_{d_{1}=1}^{D_{1}} \eta_{d_{1}} z_{d_{1} j}\right) \leq 0,
\end{aligned}
$$$$
j=1, \cdots, n,
$$$$
\sum_{r_{4}=1}^{R_{4}} u_{r_{4}} y_{r_{4} j}-\left(\sum_{i_{4}=1}^{I_{4}} v_{i_{4}} x_{i_{4} j}+\sum_{d_{2}=1}^{D_{2}} \eta_{d_{2}} z_{d_{2} j}\right) \leq 0
$$$$
j=1, \cdots, n,
$$$$
\eta_{d_{1}}, \eta_{d_{2}}, u_{r_{1}}, u_{r_{2}}, u_{r_{3}}, u_{r_{4}}, v_{i_{1}}, v_{i_{2}}, v_{i_{3}}, v_{i_{4}} \geq \varepsilon
$$$$
d_{1}=1,2, \cdots, D_{1} ; \quad d_{2}=1,2, \cdots, D_{2} ;
$$$$
r_{1}=1,2, \cdots, R_{1} ; \quad r_{2}=1,2, \cdots, R_{2} ;
$$$$
r_{3}=1,2, \cdots, R_{3} ; \quad r_{4}=1,2, \cdots, R_{4} ;
$$$$
i_{1}=1,2, \cdots, I_{1} ; \quad i_{2}=1,2, \cdots, I_{2}
$$$$
i_{3}=1,2, \cdots, I_{3} ; \quad i_{4}=1,2, \cdots, I_{4} \text {. }
$$

For determining the value of $\theta_{o}^{1 F-\max }$ with the assistance of Model 7, Model 4 is modified, which is converted into the following model.

\section{Model 8}

$$
\begin{gathered}
\theta_{o}^{12 F *}=\max \left\{\theta_{o}^{1 F} \cdot \theta_{o}^{2 F} \mid \theta_{j}^{L} \leq 1, \theta_{j}^{1 F} \leq 1, \theta_{j}^{2 F} \leq 1,\right. \\
\left.\theta_{o}^{L}=\theta_{o}^{L *}, \theta_{o}^{1 F}=\frac{O_{o}^{2}}{I_{o}^{2}}, \theta_{o}^{1 F} \in\left[0, \theta_{o}^{1 F-\max }\right]\right\} .
\end{gathered}
$$

It should be observed that in the case of Model 8, $\theta_{o}^{1 F}$ represents a variable in the objective function and that the constraint that specifies this variable together with its interval modification was incorporated into the model. Model 8 is a fractional model and it is modified into the linear model through the CharnesCooper conversion [64] similar to that given below:

\section{Model 9}

$$
\theta_{o}^{12 F *}=\max \theta_{o}^{1 F} \cdot \sum_{r_{4}=1}^{R_{4}} u_{r_{4}} y_{r_{4} o}
$$

s.t.:

$$
\begin{aligned}
& \sum_{i_{4}=1}^{I_{4}} v_{i_{4}} x_{i_{4} o}+\sum_{d_{2}=1}^{D_{2}} \eta_{d_{2}} z_{d_{2} o}=1, \\
& \sum_{d_{1}=1}^{D_{1}} \eta_{d_{1}} z_{d_{1} j}+\sum_{r_{2}=1}^{R_{2}} u_{r_{2}} y_{r_{2} j}-\sum_{r_{1}=1}^{R_{1}} u_{r_{1}} y_{r_{1} j} \\
& \quad-\left(\sum_{i_{1}=1}^{I_{1}} v_{i_{1}} x_{i_{1} j}-\sum_{i_{2}=1}^{I_{2}} v_{i_{2}} x_{i_{2} j}\right) \leq 0,
\end{aligned}
$$

$$
j=1, \cdots, n,
$$

$$
\begin{aligned}
& \sum_{d_{2}=1}^{D_{2}} \eta_{d_{2}} z_{d_{2} j}-\sum_{r_{3}=1}^{R_{3}} u_{r_{3}} y_{r_{3} j} \\
&-\left(\sum_{i_{3}=1}^{I_{3}} v_{i_{3}} x_{i_{3} j}+\sum_{d_{1}=1}^{D_{1}} \eta_{d_{1}} z_{d_{1} j}\right) \leq 0,
\end{aligned}
$$

$$
j=1, \cdots, n,
$$

$$
\sum_{r_{4}=1}^{R_{4}} u_{r_{4}} y_{r_{4} j}-\left(\sum_{i_{4}=1}^{I_{4}} v_{i_{4}} x_{i_{4} j}+\sum_{d_{2}=1}^{D_{2}} \eta_{d_{2}} z_{d_{2} j}\right) \leq 0
$$

$$
j=1, \cdots, n,
$$

$$
\begin{aligned}
& \sum_{d_{1}=1}^{D_{1}} \eta_{d_{1}} z_{d_{1} o}+\sum_{r_{2}=1}^{R_{2}} u_{r_{2}} y_{r_{2} o}-\sum_{r_{1}=1}^{R_{1}} u_{r_{1}} y_{r_{1} o} \\
& -\theta_{o}^{L *}\left(\sum_{i_{1}=1}^{I_{1}} v_{i_{1}} x_{i_{1} o}-\sum_{i_{2}=1}^{I_{2}} v_{i_{2}} x_{i_{2} o}\right)=0
\end{aligned}
$$




$$
\begin{aligned}
& \sum_{d_{2}=1}^{D_{2}} \eta_{d_{2}} z_{d_{2} o}-\sum_{r_{3}=1}^{R_{3}} u_{r_{3}} y_{r_{3} o} \\
& \quad-\theta_{o}^{1 F *}\left(\sum_{i_{3}=1}^{I_{3}} v_{i_{3}} x_{i_{3} o}+\sum_{d_{1}=1}^{D_{1}} \eta_{d_{1}} z_{d_{1} o}\right)=0 \\
& \theta_{o}^{1 F} \in\left[0, \theta_{o}^{1 F-\max ]},\right. \\
& \eta_{d_{1}}, \eta_{d_{2}}, u_{r_{1}}, u_{r_{2}}, u_{r_{3}}, u_{r_{4}}, v_{i_{1}}, v_{i_{2}}, v_{i_{3}}, v_{i_{4}} \geq \varepsilon ; \\
& d_{1}=1,2, \cdots, D_{1} ; \quad d_{2}=1,2, \cdots, D_{2} ; \\
& r_{1}=1,2, \cdots, R_{1} ; \quad r_{2}=1,2, \cdots, R_{2} ; \\
& r_{3}=1,2, \cdots, R_{3} ; \quad r_{4}=1,2, \cdots, R_{4} ; \\
& i_{1}=1,2, \cdots, I_{1} ; \quad i_{2}=1,2, \cdots, I_{2} ; \\
& i_{3}=1,2, \cdots, I_{3} ; \quad i_{4}=1,2, \cdots, I_{4} .
\end{aligned}
$$

In Model 9, by utilizing Eq.(6), the value of $k_{1}$ increases from (0) to a high level so that the model can be solved with the new $\theta_{o}^{1 F}$ each time. All the returns of the conditions of the $k_{1}$ model are resolved and the responses with $\theta_{o}^{12 F}\left(k_{1}\right)$ are illustrated. By comparing the overall values of $\theta_{o}^{12 F}\left(k_{1}\right)$, we denotes $\theta_{o}^{12 F *}$ as the maximal efficiency of the total sum of the follower stages. It should be noted that we have tested our proposed method in two modes and each time have taken one stage into consideration as variables. Given that the efficiency of a stage is unique at this point, the results of these two methods are outstandingly similar to each other, and one of these two conditions is broached to describe the above approach.

\subsection{A heuristic technique to solve the pessimistic view}

In the case of the analogous optimistic approach, $\varphi_{o}^{1 F}$ is considered a variable in the objective function Model 8 that varies at the interval $\left[\varphi_{o}^{1 F-\min }, M\right] \cdot \varphi_{o}^{1 F}$ is represented in the following fashion so that we can move it within the interval:

$$
\begin{aligned}
& \varphi_{o}^{1 F}=\varphi_{o}^{1 F-\min }+k_{1} \Delta \varepsilon \\
& k_{1}=0,1, \cdots,\left[\frac{M-\varphi_{o}^{1 F-\min }}{\Delta \varepsilon}\right]+1 .
\end{aligned}
$$

We take " $M$ " as a larger value and $\Delta \varepsilon$ as a similar optimistic approach characterized by a step size and a very small value. Moreover, $\varphi_{o}^{1 F-\min }$ is the minimal pessimistic efficiency of the first follower stage, and its value can be computed using the following model.

\section{Model 10}

$$
\begin{gathered}
\varphi_{o}^{1 F-\min }=\min \left\{\varphi_{o}^{1 F} \mid \varphi_{j}^{L} \geq 1, \varphi_{j}^{1 F} \geq 1, \varphi_{j}^{2 F} \geq 1,\right. \\
j=1, \cdots, n\} .
\end{gathered}
$$

The entire variables are non-negative in Model 10. The aforesaid models have attained minimum efficiency for the first follower stage on conditions that the efficiency of the stages be higher than (1). This model is fractional and is converted into a linear model through Charnes-Cooper conversion [64], as given below:

\section{Model 11}

$$
\varphi_{o}^{1 F-\min *}=\min \sum_{d_{2}=1}^{D_{2}} \eta_{d_{2}} z_{d_{2} o}-\sum_{r_{3}=1}^{R_{3}} u_{r_{3}} y_{r_{3} o},
$$

s.t.:

$$
\begin{aligned}
& \sum_{i_{3}=1}^{I_{3}} v_{i_{3}} x_{i_{3} o}+\sum_{d_{1}=1}^{D_{1}} \eta_{d_{1}} z_{d_{1} o}=1 \\
& \sum_{d_{1}=1}^{D_{1}} \eta_{d_{1}} z_{d_{1} j}+\sum_{r_{2}=1}^{R_{2}} u_{r_{2}} y_{r_{2} j}-\sum_{r_{1}=1}^{R_{1}} u_{r_{1}} y_{r_{1} j} \\
& \quad-\left(\sum_{i_{1}=1}^{I_{1}} v_{i_{1}} x_{i_{1} j}-\sum_{i_{2}=1}^{I_{2}} v_{i_{2}} x_{i_{2} j}\right) \geq 0,
\end{aligned}
$$

$$
j=1, \cdots, n,
$$$$
\sum_{d_{2}=1}^{D_{2}} \eta_{d_{2}} z_{d_{2} j}-\sum_{r_{3}=1}^{R_{3}} u_{r_{3}} y_{r_{3} j}
$$$$
-\left(\sum_{i_{3}=1}^{I_{3}} v_{i_{3}} x_{i_{3} j}+\sum_{d_{1}=1}^{D_{1}} \eta_{d_{1}} z_{d_{1} j}\right) \geq 0
$$

$$
j=1, \cdots, n,
$$$$
\sum_{r_{4}=1}^{R_{4}} u_{r_{4}} y_{r_{4} j}-\left(\sum_{i_{4}=1}^{I_{4}} v_{i_{4}} x_{i_{4} j}+\sum_{d_{2}=1}^{D_{2}} \eta_{d_{2}} z_{d_{2} j}\right) \geq 0
$$

$$
j=1, \cdots, n,
$$

$\eta_{d_{1}}, \eta_{d_{2}}, u_{r_{1}}, u_{r_{2}}, u_{r_{3}}, u_{r_{4}}, v_{i_{1}}, v_{i_{2}}, v_{i_{3}}, v_{i_{4}} \geq \varepsilon$

$d_{1}=1,2, \cdots, D_{1} ; \quad d_{2}=1,2, \cdots, D_{2} ;$

$r_{1}=1,2, \cdots, R_{1} ; \quad r_{2}=1,2, \cdots, R_{2} ;$

$r_{3}=1,2, \cdots, R_{3} ; \quad r_{4}=1,2, \cdots, R_{4} ;$

$i_{1}=1,2, \cdots, I_{1} ; \quad i_{2}=1,2, \cdots, I_{2} ;$

$i_{3}=1,2, \cdots, I_{3} ; \quad i_{4}=1,2, \cdots, I_{4}$. 
By determining the value of $\varphi_{o}^{1 F-\text { min }}$ using Model 11, Model 5 is converted into Model 12 as follows:

\section{Model 12}

$$
\begin{aligned}
\varphi_{o}^{12 F *}= & \min \left\{\varphi_{o}^{1 F} \cdot \varphi_{o}^{2 F} \mid \varphi_{j}^{L} \geq 1, \varphi_{j}^{1 F} \geq 1, \varphi_{j}^{2 F} \geq 1,\right. \\
& \left.\varphi_{o}^{L}=\varphi_{o}^{L *}, \varphi_{o}^{1 F}=\frac{O_{o}^{2}}{I_{o}^{2}}, \varphi_{o}^{1 F} \in\left[\varphi_{o}^{1 F-\min }, M\right]\right\} .
\end{aligned}
$$

It should be noted that similar to the optimistic approach in Model $12, \varphi_{o}^{1 F}$ in the objective function is considered as a variable, and a constraint determining this variable as well as its interval modification was incorporated into the model. Model 12 is fractional and is converted into a linear model through CharnesCooper conversion [64] as follows:

\section{Model 13}

$\varphi_{o}^{12 F *}=\min \varphi_{o}^{1 F} \cdot \sum_{r_{4}=1}^{R_{4}} u_{r_{4}} y_{r_{4} o}$

s.t.:

$$
\begin{aligned}
& \sum_{i_{4}=1}^{I_{4}} v_{i_{4}} x_{i_{4} o}+\sum_{d_{2}=1}^{D_{2}} \eta_{d_{2}} z_{d_{2} o}=1 \\
& \sum_{d_{1}=1}^{D_{1}} \eta_{d_{1}} z_{d_{1} j}+\sum_{r_{2}=1}^{R_{2}} u_{r_{2}} y_{r_{2} j}-\sum_{r_{1}=1}^{R_{1}} u_{r_{1}} y_{r_{1} j} \\
& \quad-\left(\sum_{i_{1}=1}^{I_{1}} v_{i_{1}} x_{i_{1} j}-\sum_{i_{2}=1}^{I_{2}} v_{i_{2}} x_{i_{2} j}\right) \geq 0
\end{aligned}
$$$$
j=1, \cdots, n,
$$$$
\sum_{d_{2}=1}^{D_{2}} \eta_{d_{2}} z_{d_{2} j}-\sum_{r_{3}=1}^{R_{3}} u_{r_{3}} y_{r_{3} j}
$$$$
-\left(\sum_{i_{3}=1}^{I_{3}} v_{i_{3}} x_{i_{3} j}+\sum_{d_{1}=1}^{D_{1}} \eta_{d_{1}} z_{d_{1} j}\right) \geq 0
$$$$
j=1, \cdots, n,
$$$$
\sum_{r_{4}=1}^{R_{4}} u_{r_{4}} y_{r_{4} j}-\left(\sum_{i_{4}=1}^{I_{4}} v_{i_{4}} x_{i_{4} j}+\sum_{d_{2}=1}^{D_{2}} \eta_{d_{2}} z_{d_{2} j}\right) \geq 0
$$

$$
j=1, \cdots, n,
$$$$
\sum_{d_{1}=1}^{D_{1}} \eta_{d_{1}} z_{d_{1} o}+\sum_{r_{2}=1}^{R_{2}} u_{r_{2}} y_{r_{2} o}-\sum_{r_{1}=1}^{R_{1}} u_{r_{1}} y_{r_{1} o}
$$

$$
-\varphi_{o}^{L *}\left(\sum_{i_{1}=1}^{I_{1}} v_{i_{1}} x_{i_{1} o}-\sum_{i_{2}=1}^{I_{2}} v_{i_{2}} x_{i_{2} o}\right)=0
$$

$$
\begin{aligned}
& \sum_{d_{2}=1}^{D_{2}} \eta_{d_{2}} z_{d_{2} o}-\sum_{r_{3}=1}^{R_{3}} u_{r_{3}} y_{r_{3} o} \\
& \quad-\varphi_{o}^{1 F *}\left(\sum_{i_{3}=1}^{I_{3}} v_{i_{3}} x_{i_{3} o}+\sum_{d_{1}=1}^{D_{1}} \eta_{d_{1}} z_{d_{1} o}\right)=0 \\
& \varphi_{o}^{1 F} \in\left[\varphi_{o}^{1 F-\min }, M\right]
\end{aligned}
$$

$\eta_{d_{1}}, \eta_{d_{2}}, u_{r_{1}}, u_{r_{2}}, u_{r_{3}}, u_{r_{4}}, v_{i_{1}}, v_{i_{2}}, v_{i_{3}}, v_{i_{4}} \geq \varepsilon$

$d_{1}=1,2, \cdots, D_{1} ; \quad d_{2}=1,2, \cdots, D_{2} ;$

$r_{1}=1,2, \cdots, R_{1} ; \quad r_{2}=1,2, \cdots, R_{2} ;$

$r_{3}=1,2, \cdots, R_{3} ; \quad r_{4}=1,2, \cdots, R_{4} ;$

$i_{1}=1,2, \cdots, I_{1} ; \quad i_{2}=1,2, \cdots, I_{2} ;$

$i_{3}=1,2, \cdots, I_{3} ; \quad i_{4}=1,2, \cdots, I_{4}$.

In Model 13, by utilizing Eq. (7), the value of $k_{1}$ is increased from (0) to a high degree so that we can resolve the model with the new $\varphi_{o}^{1 F}$. We solve all the returns of the conditions associated with $k_{1}$ models and show the responses with $\varphi_{o}^{12 F}\left(k_{1}\right)$. Based on a comparison of all the values of $\varphi_{o}^{12 F}\left(k_{1}\right), \varphi_{o}^{12 F *}$ denotes the minimal efficiency of $\varphi_{o}^{12 F}\left(k_{1}\right)$ in Figure 1 from the pessimistic view. It should be observed that we have tested our proposed method in two modes and each time have taken one stage into consideration as variables. Given that the efficiency of a stage is unique at this point, the results of these two methods are outstandingly similar to each other and for further elaboration, we have broached one of these two conditions to describe the proposed approach.

\section{Case study description}

According to the statistics released by the Iranian Health Reference Laboratory, 5611 MDLs (public and private sectors) are operating in the country. The shares of the public and private sectors are 57 and $43 \%$, respectively. There are 933 active MDLs in Tehran, which include $16.7 \%$ of the total share of the country. Of these, $71 \%$ and $29 \%$ are managed by the private and public sectors, respectively. The statistics show that unlike the number of MDLs most of which are available to the public sector in the country, the majority of the MDLs are under private sector management in Tehran. Due to the importance of the private sector in Tehran, our case study is related to the private MDLs 


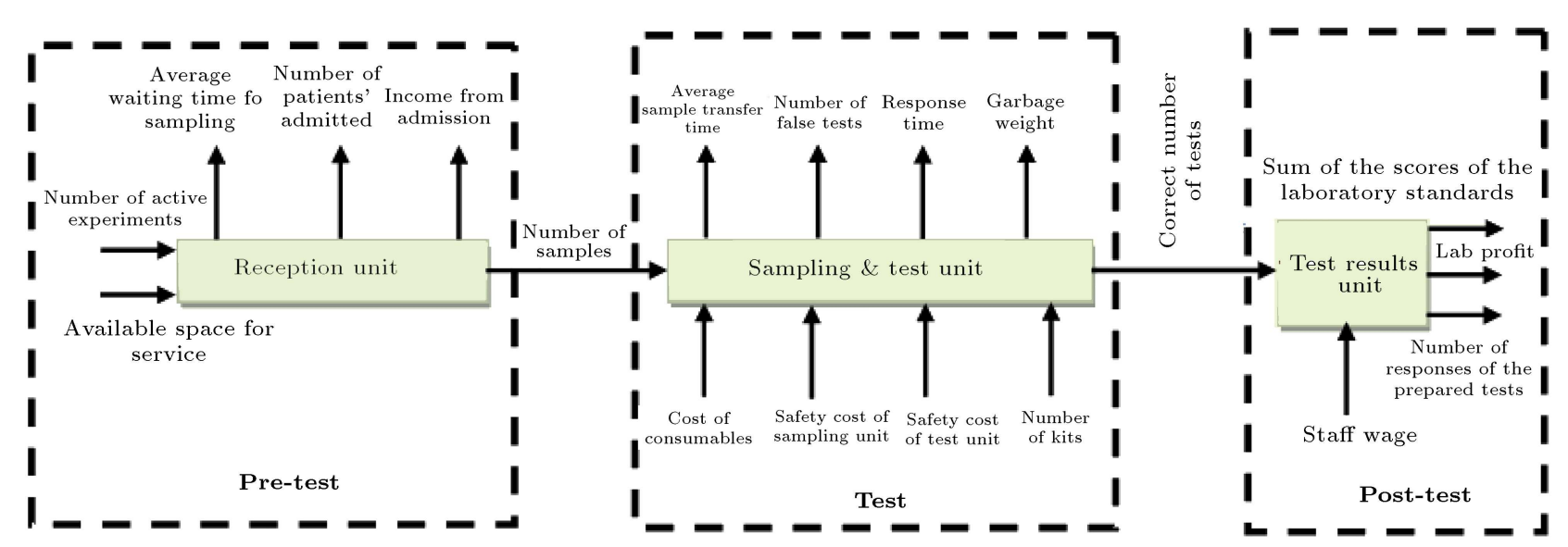

Figure 3. Three-stage network of an MDL.

Table 8. Variables of input, intermediary, and output.

\begin{tabular}{lll}
\hline \multicolumn{1}{c}{ Input variables } & \multicolumn{1}{c}{ Intermediary variables } & \multicolumn{1}{c}{ Output variables } \\
\hline Number of active experiments $\left(x_{1}\right)$ & Number of samples $\left(z_{1}\right)$ & Average waiting time for sampling $\left(y_{1}\right)$ \\
$\begin{array}{l}\text { Available pace for service }\left(x_{2}\right) \\
\text { Cost of consumables }\left(x_{3}\right)\end{array}$ & Correct number of tests $\left(z_{2}\right)$ & Number of patients' admission $\left(y_{2}\right)$ \\
Safety cost of sampling unit $\left(x_{4}\right)$ & & Income from admission $\left(y_{3}\right)$ \\
Safety cost of test unit $\left(x_{5}\right)$ & Average sample transfer time $\left(y_{4}\right)$ \\
Number of kits $\left(x_{6}\right)$ & Number of false tests $\left(y_{5}\right)$ \\
Staff wage $\left(x_{7}\right)$ & Test response time $\left(y_{6}\right)$ \\
& Garbage weight $\left(y_{7}\right)$ \\
& Number of responses of the prepared tests $\left(y_{8}\right)$ \\
& Sum of the scores of the laboratory standards $\left(y_{9}\right)$ \\
\hline
\end{tabular}

of Tehran. In this regard, the sample size in this study includes 25 MDLs selected by cluster sampling from private MDLs in Tehran. In this segment, we will study the performance of private MDLs in Tehran. MDLs contain three main processes (pre-test, test, and posttest), as shown in Figure 3.

To evaluate the efficiency of the MDL, environmental, social, and economic criteria are considered. Cost of consumables, income from admission, MDL profit, and staff wage are introduced as economic criteria. Staff safety as a social criterion is the cost that each service center pays against the dangers and accidents which may occur in the workplace. This criterion is considered to protect the health of the staff, patients, and other clients as well as preserve the environment. The variables are shown in Table 8 . We have many variables of inputs and outputs. Therefore, Tables 9 and 10 provide the data belonging to the year 2017. The inputs are shown in Table 9 and the outputs are rendered in Table 10. Thereby, the efficiency of the structure, as shown in Figure 3, is measured from both optimistic and pessimistic views.

According to the opinions of the experts, we consider the step size in the models $\Delta \varepsilon=0.01, M=3$, and $\varepsilon=0.001$. We implemented the proposed heuristic approach for the two Models 4 and 5. The values obtained for the first follower are shown in Table 11.

Based on the values of $k_{1}$, it can be found that the optimal values of the network, as shown in Figure 2, reportedly occur when the first follower is at maximum and minimum values. For this reason, all values of $k_{1}$ vanish. Table 12 shows the efficiencies based on the optimistic, pessimistic, and double-frontier views.

In Table 12, the maximum and minimum mean efficiency of the course is shown in gray and green, respectively. According to the second column of Table 12, the efficiency scores of period 22 are the highest with the total efficiency of 1 . In addition, the efficiency scores of period 12 are the lowest with the total efficiency of 0.228176 from the optimistic viewpoint. From the third, fourth, and fifth columns of Table 12, it is noted that the average optimistic efficiency values of the leader, first follower, and second follower take the values $0.73,0.99,0.82$, respectively. Of note, the DMU proves to have a better condition if the efficiency value is closer to (1) and the efficiency 
Table 9. Set of inputs and intermediate measures for the 25 diagnostic laboratories in 2017.

\begin{tabular}{|c|c|c|c|c|c|c|c|c|c|}
\hline DMU & $x_{1}$ & $x_{2}$ & $x_{3}$ & $x_{4}$ & $x_{5}$ & $x_{6}$ & $x_{7}$ & $z_{1}$ & $z_{2}$ \\
\hline 1 & 0.6 & 0.652 & 0.841 & 0.873 & 0.693 & 0.873 & 0.69 & 0.812 & 0.874 \\
\hline 2 & 1 & 0.739 & 0.865 & 0.927 & 1 & 0.927 & 0.739 & 0.857 & 0.925 \\
\hline 3 & 0.583 & 0.822 & 0.631 & 0.677 & 0.663 & 0.677 & 0.559 & 0.629 & 0.669 \\
\hline 4 & 0.592 & 0.77 & 0.502 & 0.538 & 0.667 & 0.538 & 0.941 & 0.5 & 0.535 \\
\hline 5 & 0.85 & 0.87 & 0.932 & 1 & 0.933 & 1 & 0.919 & 0.929 & 1 \\
\hline 6 & 0.817 & 0.713 & 0.817 & 0.877 & 0.837 & 0.877 & 0.31 & 0.814 & 0.872 \\
\hline 7 & 0.3 & 0.665 & 0.617 & 0.662 & 0.6 & 0.662 & 0.592 & 0.614 & 0.66 \\
\hline 8 & 0.35 & 0.722 & 0.574 & 0.615 & 0.733 & 0.158 & 1 & 0.571 & 0.616 \\
\hline 9 & 0.867 & 0.865 & 0.789 & 0.835 & 1 & 0.835 & 0.362 & 0.786 & 0.834 \\
\hline 10 & 0.75 & 0.8 & 0.645 & 0.69 & 0.77 & 0.69 & 0.017 & 0.643 & 0.689 \\
\hline 11 & 0.5 & 0.778 & 0.717 & 0.765 & 0.673 & 0.765 & 0.931 & 0.714 & 0.764 \\
\hline 12 & 0.717 & 0.565 & 0.445 & 0.474 & 0.7 & 0.474 & 0.655 & 0.443 & 0.474 \\
\hline 13 & 0.233 & 1 & 0.288 & 0.311 & 0.333 & 0.311 & 0.097 & 0.107 & 0.285 \\
\hline 14 & 0.85 & 0.804 & 0.857 & 0.873 & 0.96 & 0.873 & 0.626 & 0.32 & 0.855 \\
\hline 15 & 0.317 & 0.787 & 0.289 & 0.295 & 0.667 & 0.295 & 0.099 & 0.077 & 0.293 \\
\hline 16 & 0.25 & 0.826 & 0.482 & 0.502 & 0.74 & 0.502 & 0.242 & 0.162 & 0.484 \\
\hline 17 & 0.55 & 0.717 & 0.699 & 0.707 & 0.9 & 0.707 & 0.341 & 0.279 & 0.699 \\
\hline 18 & 0.283 & 0.783 & 0.305 & 0.307 & 0.68 & 0.307 & 0.17 & 0.285 & 0.306 \\
\hline 19 & 0.333 & 0.878 & 0.417 & 0.428 & 0.66 & 0.428 & 0.35 & 0.301 & 0.417 \\
\hline 20 & 0.667 & 0.691 & 0.29 & 0.292 & 0.333 & 0.292 & 0.425 & 0.271 & 0.29 \\
\hline 21 & 0.65 & 0.87 & 0.076 & 0.076 & 0.333 & 0.076 & 0.038 & 0.028 & 0.075 \\
\hline 22 & 0.517 & 0.891 & 0.649 & 0.647 & 0.333 & 0.647 & 0.273 & 0.607 & 0.643 \\
\hline 23 & 0.258 & 0.8 & 0.304 & 0.302 & 0.7 & 0.302 & 0.124 & 0.257 & 0.301 \\
\hline 24 & 0.917 & 0.835 & 1 & 0.997 & 0.767 & 0.997 & 0.776 & 1 & 0.993 \\
\hline 25 & 0.367 & 0.809 & 0.324 & 0.331 & 0.677 & 0.331 & 0.281 & 0.214 & 0.33 \\
\hline
\end{tabular}

value is farther from (1) based on the pessimistic standpoint. The sixth column of Table 12 shows that the efficiency scores of period 22 are the highest with the total efficiency of 3.80496, whereas units 2, 12, 14, $15,20,21,24$, and 25 characterized by a common and overall efficiency of 1 are the worst units from the pessimistic view. Similarly, results demonstrate that the average pessimistic efficiency values of the leader and the first and second followers are (1.88, 1.04 , and 1.32), respectively. Based on all the results, the difference between optimistic and pessimistic views can be observed. Given that this paper proposes a double-frontier approach to evaluating the overall efficiency, the best and poorest DMUs are units 22 and 25 with the overall efficiencies of 2.804719 and 0.541537, respectively (Column 10 of Table 12). In order to conduct the final ranking, the double-frontier view is used as illuminated in Eq. (5). Therefore, the efficiency values of 25 DMUs are rated in Table 13 .

The third and sixth columns of Table 13 demonstrate the clustering of DMUs by using k-means method based on the double-frontier view explained in Section 3. Table 13 reports that units $7,18,19$, and 22 are located in the first cluster. Units $1,2,3,5,6,8$, $9,11,13,16$, and 17 are placed in the second cluster. Also, units 4, 10, 12, 14, 15, 20, 21, 23, 24, and 25 are placed in the third cluster.

Today, medical sciences depend on laboratory diagnosis to discover the cause of the disease as well as on timely and rapid treatment. Accordingly, the number of diagnostic laboratories is increasing day by day in different cities of the world. Therefore, trying to 
Table 10. Set of outputs for the 25 diagnostic laboratories in 2017.

\begin{tabular}{|c|c|c|c|c|c|c|c|c|c|c|}
\hline DMU & $y_{1}$ & $y_{2}$ & $y_{3}$ & $y_{4}$ & $y_{5}$ & $y_{6}$ & $y_{7}$ & $y_{8}$ & $y_{9}$ & $y_{10}$ \\
\hline 1 & 0.423 & 0.351 & 0.876 & 0.125 & 0.075 & 0.036 & 0.451 & 0.351 & 0.98 & 1 \\
\hline 2 & 0.462 & 0.899 & 0.916 & 0.25 & 0.051 & 0.012 & 0.522 & 0.899 & 0.82 & 0.749 \\
\hline 3 & 0.423 & 0.505 & 0.673 & 0.083 & 0.061 & 0.03 & 0.273 & 0.505 & 0.64 & 0.951 \\
\hline 4 & 0.538 & 0.496 & 0.535 & 0.167 & 0.047 & 0.143 & 0.32 & 0.496 & 0.55 & 0.502 \\
\hline 5 & 0.5 & 0.829 & 0.978 & 0.375 & 0.033 & 0.06 & 0.53 & 0.829 & 0.44 & 0.89 \\
\hline 6 & 0.615 & 0.789 & 0.865 & 0.167 & 0.047 & 0.286 & 0.261 & 0.789 & 0.725 & 0.863 \\
\hline 7 & 0.615 & 0.428 & 0.647 & 0.75 & 0.042 & 1 & 0.266 & 0.428 & 0.675 & 0.827 \\
\hline 8 & 0.692 & 0.416 & 0.591 & 0.063 & 0.047 & 0.036 & 0.387 & 0.416 & 0.49 & 0.254 \\
\hline 9 & 0.692 & 0.865 & 0.838 & 0.25 & 0.037 & 0.286 & 0.542 & 0.865 & 0.85 & 0.529 \\
\hline 10 & 0.692 & 0.468 & 0.692 & 0.271 & 0.037 & 0.048 & 0.564 & 0.468 & 0.425 & 0.75 \\
\hline 11 & 0.615 & 0.522 & 0.767 & 0.313 & 0.047 & 0.018 & 0.266 & 0.522 & 0.525 & 0.964 \\
\hline 12 & 0.654 & 0.427 & 0.476 & 0.104 & 0.051 & 0.143 & 0.325 & 0.427 & 0.575 & 0.286 \\
\hline 13 & 0.269 & 0.107 & 0.312 & 0.125 & 0.173 & 0.143 & 0.278 & 0.107 & 0.5 & 0.416 \\
\hline 14 & 0.5 & 0.323 & 0.875 & 0.25 & 0.252 & 0.429 & 0.608 & 0.323 & 0.5 & 0.936 \\
\hline 15 & 0.5 & 0.134 & 0.295 & 0.125 & 0.262 & 0.429 & 0.581 & 0.115 & 0.975 & 0.357 \\
\hline 16 & 0.538 & 0.279 & 0.503 & 0.167 & 0.374 & 0.143 & 0.601 & 0.277 & 1 & 0.495 \\
\hline 17 & 0.692 & 0.465 & 0.71 & 0.063 & 0.294 & 0.036 & 0.648 & 0.465 & 0.94 & 0.691 \\
\hline 18 & 0.615 & 0.489 & 0.308 & 0.208 & 0.336 & 0.054 & 0.591 & 0.489 & 0.69 & 0.249 \\
\hline 19 & 0.577 & 0.567 & 0.429 & 0.375 & 0.318 & 0.03 & 0.665 & 0.567 & 0.725 & 0.348 \\
\hline 20 & 0.615 & 0.477 & 0.293 & 0.75 & 0.341 & 1 & 0.606 & 0.477 & 0.69 & 0.198 \\
\hline 21 & 0.385 & 0.038 & 0.076 & 1 & 0.196 & 0.143 & 0.347 & 0.038 & 0.84 & 0.072 \\
\hline 22 & 0.846 & 1 & 0.649 & 0.063 & 0.794 & 0.03 & 0.704 & 1 & 1 & 0.594 \\
\hline 23 & 0.423 & 0.098 & 0.303 & 0.146 & 0.187 & 0.286 & 0.475 & 0.098 & 0.55 & 0.268 \\
\hline 24 & 1 & 0.596 & 1 & 0.25 & 1 & 0.042 & 1 & 0.596 & 0.94 & 0.914 \\
\hline 25 & 0.462 & 0.104 & 0.332 & 0.125 & 0.257 & 0.018 & 0.502 & 0.104 & 1 & 0.291 \\
\hline
\end{tabular}

Table 11. Values of the maximum and minimum efficiencies of the first follower.

\begin{tabular}{|c|c|c|c|c|c|c|c|c|c|}
\hline \multirow{2}{*}{ DMU } & \multicolumn{2}{|c|}{ Optimistic view } & \multicolumn{2}{|c|}{ Pessimistic view } & \multirow{2}{*}{ DMU } & \multicolumn{2}{|c|}{ Optimistic view } & \multicolumn{2}{|c|}{ Pessimistic view } \\
\hline & $k_{1}$ & $\theta_{o}^{1 F-\max }$ & $k_{1}$ & $\varphi_{0}^{1 F-\min }$ & & $k_{1}$ & $\theta_{o}^{1 F-\max }$ & $k_{1}$ & $\varphi_{0}^{1 F-\min }$ \\
\hline 1 & 0 & 1 & 0 & 1.06362 & 14 & 0 & 1 & 0 & 1.02517 \\
\hline 2 & 0 & 1 & 0 & 1.08218 & 15 & 0 & 0.993 & 0 & 1.02923 \\
\hline 3 & 0 & 1 & 0 & 1.07317 & 16 & 0 & 0.96213 & 0 & 1.02001 \\
\hline 4 & 0 & 0.99185 & 0 & 1.07551 & 17 & 0 & 1 & 0 & 1.0248 \\
\hline 5 & 0 & 1 & 0 & 1.08612 & 18 & 0 & 0.99188 & 0 & 1.01567 \\
\hline 6 & 0 & 1 & 0 & 1.0782 & 19 & 0 & 0.97203 & 0 & 1.01635 \\
\hline 7 & 0 & 1 & 0 & 1.06064 & 20 & 0 & 0.9905 & 0 & 1 \\
\hline 8 & 0 & 1 & 0 & 1.08898 & 21 & 0 & 0.98689 & 0 & 1 \\
\hline 9 & 0 & 0.99718 & 0 & 1.07487 & 22 & 0 & 1 & 0 & 1.01478 \\
\hline 10 & 0 & 1 & 0 & 1.08286 & 23 & 0 & 1 & 0 & 1.00491 \\
\hline 11 & 0 & 1 & 0 & 1.08152 & 24 & 0 & 0.99346 & 0 & 1.02735 \\
\hline 12 & 0 & 0.99589 & 0 & 1.07942 & 25 & 0 & 1 & 0 & 1.0314 \\
\hline 13 & 0 & 0.99706 & 0 & 1 & & & & & \\
\hline
\end{tabular}


Table 12. Results based on the optimistic, pessimistic, and double-frontier views.

\begin{tabular}{|c|c|c|c|c|c|c|c|c|c|}
\hline \multirow[b]{2}{*}{ DMU } & \multicolumn{4}{|c|}{ Optimistic view } & \multicolumn{4}{|c|}{ Pessimistic view } & \multirow{2}{*}{$\begin{array}{l}\begin{array}{l}\text { Double- } \\
\text { frontier }\end{array} \\
\phi_{o}^{\text {overall* }} \\
\end{array}$} \\
\hline & $\theta_{o}^{\text {overall* }}$ & $\theta_{o}^{L *}$ & $\theta_{o}^{1 F *}$ & $\theta_{o}^{2 F *}$ & $\varphi_{o}^{\text {overall* }}$ & $\varphi_{o}^{L *}$ & $\varphi_{o}^{1 F *}$ & $\varphi_{o}^{2 F *}$ & \\
\hline 1 & 0.79044 & 1 & 1 & 0.79044 & 1.725818 & 1.52304 & 1.06362 & 1.065362 & 1.167971 \\
\hline 2 & 0.74755 & 1 & 1 & 0.74755 & 1.45366 & $\underline{1}$ & 1.08218 & 1.34327 & 1.042441 \\
\hline 3 & 0.88415 & 0.88415 & 1 & 1 & 3.190746 & 1.92187 & 1.07317 & 1.547034 & 1.679612 \\
\hline 4 & 0.428705 & 0.53989 & 0.99185 & 0.800585 & 2.229599 & 1.73271 & 1.07551 & 1.196428 & 0.977671 \\
\hline 5 & 0.74256 & 1 & 1 & 0.74256 & 2.04121 & 1.87936 & 1.08612 & $\underline{1}$ & 1.231146 \\
\hline 6 & 0.719244 & 0.82592 & 1 & 0.87084 & 2.44752 & 1.68241 & 1.0782 & 1.349258 & 1.326787 \\
\hline 7 & 0.88457 & 1 & 1 & 0.88457 & 5.331549 & 3.55631 & 1.06064 & 1.413467 & 2.171665 \\
\hline 8 & 0.358562 & 0.80945 & 1 & $\underline{0.44297}$ & 3.152826 & 2.89521 & 1.08898 & $\underline{1}$ & 1.063242 \\
\hline 9 & 0.510268 & 0.75612 & 0.99718 & 0.676758 & 2.60279 & 1.78698 & 1.07487 & 1.355075 & 1.152441 \\
\hline 10 & 0.43293 & 0.43293 & 1 & 1 & 1.607039 & 1.29781 & 1.08286 & 1.143518 & 0.834108 \\
\hline 11 & 0.794291 & 0.89104 & 1 & 0.89142 & 2.79557 & 2.43933 & 1.08152 & 1.059657 & 1.490133 \\
\hline 12 & $\underline{0.228176}$ & 0.36656 & 0.99589 & 0.625049 & 1.48668 & $\underline{1}$ & 1.07942 & 1.377295 & 0.58243 \\
\hline 13 & 0.99706 & 1 & 0.99706 & 1 & 1.723248 & 1.53657 & $\underline{1}$ & 1.12149 & 1.310794 \\
\hline 14 & 0.499959 & 0.66189 & 1 & 0.75535 & $\underline{1.02517}$ & $\underline{1}$ & 1.02517 & $\underline{1}$ & 0.715921 \\
\hline 15 & 0.40492 & 0.43959 & 0.993 & 0.927623 & 1.26853 & $\underline{1}$ & 1.02923 & 1.232504 & 0.716696 \\
\hline 16 & 0.76524 & 1 & $\underline{0.96213}$ & 0.79536 & 4.116656 & 2.97991 & 1.02001 & 1.354369 & 1.774889 \\
\hline 17 & 0.467305 & 0.59799 & 1 & 0.78146 & 2.636158 & 1.91630 & 1.0248 & 1.342359 & 1.109905 \\
\hline 18 & 0.99188 & 1 & 0.99188 & 1 & 6.790598 & 3.37577 & 1.01567 & 1.980535 & 2.595276 \\
\hline 19 & 0.87451 & 1 & 0.97203 & 0.899674 & 7.094439 & 3.45711 & 1.01635 & 2.019117 & 2.490815 \\
\hline 20 & 0.365762 & 0.36927 & 0.9905 & 1 & 1.65736 & $\underline{1}$ & $\underline{1}$ & 1.65736 & 0.778588 \\
\hline 21 & 0.301307 & $\underline{0.30531}$ & 0.98689 & 1 & 1.25368 & $\underline{1}$ & $\underline{1}$ & 1.25368 & 0.614608 \\
\hline 22 & 1 & 1 & 1 & 1 & 7.86645 & 3.80496 & 1.01478 & 2.037309 & 2.804719 \\
\hline 23 & 0.375131 & 0.57539 & 1 & 0.65196 & 1.316131 & 1.30970 & 1.00491 & $\underline{1}$ & 0.702653 \\
\hline 24 & 0.34704 & 0.50516 & 0.99346 & 0.691512 & 1.22495 & $\underline{1}$ & 1.02735 & 1.19234 & 0.652002 \\
\hline 25 & 0.284334 & 0.41975 & 1 & 0.67739 & 1.0314 & $\underline{1}$ & 1.0314 & $\underline{1}$ & $\underline{0.541537}$ \\
\hline
\end{tabular}

Table 13. Rank and cluster of DMUs based on the double-frontier view .

\begin{tabular}{cccccc}
\hline Unit & Rank & Cluster & Unit & Rank & Cluster \\
\hline DMU $_{22}$ & 1 & 1 & $\mathrm{DMU}_{8}$ & 14 & 2 \\
$\mathrm{DMU}_{18}$ & 2 & 1 & $\mathrm{DMU}_{2}$ & 15 & 2 \\
$\mathrm{DMU}_{19}$ & 3 & 1 & $\mathrm{DMU}_{4}$ & 16 & 3 \\
$\mathrm{DMU}_{7}$ & 4 & 1 & $\mathrm{DMU}_{10}$ & 17 & 3 \\
$\mathrm{DMU}_{16}$ & 5 & 2 & $\mathrm{DMU}_{20}$ & 18 & 3 \\
$\mathrm{DMU}_{3}$ & 6 & 2 & $\mathrm{DMU}_{15}$ & 19 & 3 \\
$\mathrm{DMU}_{11}$ & 7 & 2 & $\mathrm{DMU}_{14}$ & 20 & 3 \\
$\mathrm{DMU}_{6}$ & 8 & 2 & $\mathrm{DMU}_{23}$ & 21 & 3 \\
$\mathrm{DMU}_{13}$ & 9 & 2 & $\mathrm{DMU}_{24}$ & 22 & 3 \\
$\mathrm{DMU}_{5}$ & 10 & 2 & $\mathrm{DMU}_{21}$ & 23 & 3 \\
$\mathrm{DMU}_{1}$ & 11 & 2 & $\mathrm{DMU}_{12}$ & 24 & 3 \\
$\mathrm{DMU}_{9}$ & 12 & 2 & $\mathrm{DMU}_{25}$ & 25 & 3 \\
$\mathrm{DMU}_{17}$ & 13 & 2 & & & \\
\hline
\end{tabular}

emulate leading laboratories can be an important step for continuous enhancement of their performance. The results of this study indicate that most private labs in Tehran are not efficient. The reasons of inefficiency of laboratories can be identified as follows:
1. One of the most important sources of municipal wastes production is hospitals, health centers, physicians, clinics, and MDLs. Among them, laboratories produce a significant amount of infectious waste that is of great importance to health and the environment. Releasing this waste into the environment can cause and transmit a variety of diseases including hepatitis B, C, and AIDS. Proper management of waste performs a significant role in the performance of laboratories;

2. The standards and criteria that any laboratory system needs to be upgraded should be analyzed. Therefore, the quality management achievements in the lab include the following advantages: enhancing the accuracy of the results provided by the labs, ensuring the continuous calibration of lab equipment, standardizing the procedures for the management of laboratories, and improving the customer-oriented quality of laboratories;

3. The large coverage of services facilitates differentiating and enhancing a laboratory. Therefore, 
increasing the geographic coverage of services is essential to the functionality of each laboratory;

4. Factors such as price growth of kits show that the MDLs require expense management. On average, $45 \%$ of the total expense required is related to the consumables in every MDL.

So, the cost management has an important role in increasing efficiency. Considering the above reasons for promoting the performance of MDL, the four methods are suggested as follows:

1. Separation of laboratory wastes at the very site of production, collection, and labeling; transportation to a safe place, packing, and temporary storage; transportation from the place of production and loading; and the final disposal stage. All steps are designed according to the performance and breadth of each laboratory. All staff members should be educated and notified of the procedures in writing;

2. Investigation of the factors, determination of the status of the laboratory, recording of the results in the form of weaknesses and strengths, and determination of the gap between the existing and desired situations which may provide appropriate and effective strategies for standardizing the laboratories;

3. Provision of services at smaller laboratories in view of the increased diversity and capacity of the experiments is one of the ways in which successful labs operate. The adoption of sampling units as well as the use of information and communication knowledge are among the requirements for the coverage of services;

4. The application of the operation management method along with removing unnecessary points leads to the reduction of additional laboratory costs and increase in productivity.

\section{Conclusions}

The services of laboratory centers constitute a significant part of the activities of many health centers and research organizations. Given that the performance of clinical and research laboratories plays a vital role in ensuring the quality and efficiency of healthcare and research activities, the need for solutions to the issue of evaluating and improving their performance has attracted the attention of the world's scientific and professional communities for many years. The performance measurement at laboratory centers is also important for managers and authorities in health centers and research organizations. In doing so, they can provide areas for improvement and increase productivity in the organization upon identifying their strengths and weaknesses.
The purpose of any performance appraisal program is to enhance efficiency and effectiveness. This goal is achieved by assisting the laboratories to do their best by developing their skills and knowledge to meet the future needs of the work units. It is important that the tasks be conducted properly at laboratories that will improve the quality of the test results and increase the effectiveness of the services and research achievements. Effectiveness of services in clinical laboratories facilitates quick diagnosis of illnesses and better saving of patients' lives. Also, the effectiveness of their research achievements and their commercialization will lead to the growth and self-sufficiency of research organizations. This study measured the efficiency of the selected private Medical Diagnostic Laboratories (MDLs) in Tehran through Network Data Envelopment Analysis (NDEA) approach. In this regard, the efficiency evaluation of 25 private MDLs in Tehran was performed. To evaluate the efficiency of MDLs, there are several indicators that may be used for different approaches. However, most studies, regardless of the approach they use to evaluate, have managed to find better or more appropriate indicators. Therefore, it is important to investigate and identify the most effective factors in evaluating the performance of MDLs. Therefore, in order to facilitate a correct and well-informed decision-making in this area, given the lack of literature, identification of effective factors was done using the Fuzzy Delphi method. The Delphi team was composed of 11 members consisting of professors, administrators, technical officials, and experts in the field of private MDLs. The final indicators consisted of 7 input indicators, 3 intermediate indicators, and 9 output indicators. Of note, there are three criteria of sustainability (social, economic, and environmental) in some of the selected indicators.

The efficiency evaluation of a network opens the "black box" and deliberates on the internal structures and innermost interactions of the system. The black box method ignores the internal structure of systems and this task led to the inaccuracy of the results. This study presented the modeling method and solution for evaluating the efficiency of a complex system with additional inputs and undesirable outputs. We attempted to pay attention to the intra-system activities using the proposed model. In this study, a three-stage series structure of an MDL is simulated in the real world. This network model of three processes (the pre-test, test, and post-test processes). The pre-testing process contains the reception unit. Also, the testing process consists of the sampling and testing units. Finally, the post-test process includes the test result unit. The presented model is an innovative model and there are no similar researches in the field of MDLs for network analysis. According to managers, a non-cooperative model is used with a double-frontier method to measure 
the performance of the lab units and then, to convert nonlinear programs into linear ones by a heuristic method. This approach provides more information about inefficient units through penetration to the depth of the system. In fact, the double-frontier method views each unit from two perspectives (the optimistic and pessimistic views) and any result that implies only one of these perspectives shall be one-sided and inadequate. The evaluating efficiency using the doublefrontier method would lead to increased accuracy. The heuristic approach proposed in this research can be used to solve the three-stage system. The model becomes complex in the case of higher-stage systems due to the additional inputs and outputs, thereby increasing the solution time significantly. To overcome the problem, we can change the movement step $(\Delta \varepsilon)$.

The ranking results show that units 22 and 21 are the best and poorest units in terms of efficiency, respectively. Also, the results of clustering techniques are indicated by 4, 11, and 10 units that are placed in the first, second, and third clusters, separately. It was found that various performance indicators such as monitoring and control of wastes, geographic coverage, review of the pre-test process (the reception unit), providing appropriate and effective strategies for standardization of laboratories, and cost of consumables (kits) due to currency fluctuations were significant elements to determine efficiency. Other results of this research provide applicable indicators that can be used in future research by other researchers. The results of this research will be of assistance to the managers and the outcome might lead to improved MDL services due to the adoption of proper methods. For further research in the future, modeling should be done with imprecise data given the difficulty in gathering data. Also, since the activities of an enterprise such as MDLs are continuous, rather than sectional over a period of time, the cross-sectional efficiency assessment cannot provide a realistic response to the performance of laboratories. Therefore, network analysis in the dynamic mode is recommended.

\section{References}

1. Sohn, H., Minion, J., Albert, H., et al. "TB diagnostic tests: how do we figure out their costs?", Expert Review of Anti-Infective Therapy, 7(6), pp. 723-733 (2009).

2. Fang, C., Otero, H.J., Greenberg, D., et al. "Costutility analyses of diagnostic laboratory tests: a systematic review", Value in Health, 14(8), pp. 1010-1018 (2011).

3. Vaezi, E., Najafi, S., Hadji Molana, M., et al. "Measuring performance of a three-stage structure using data envelopment analysis and Stackelberg game", Journal of Industrial and Systems Engineering, 12(2), pp. 151173 (2019).

4. Kao, C. "Efficiency decomposition for general multistage systems in data envelopment analysis", European Journal of Operational Research, 232(1), pp. 117-124 (2014).

5. Ma, J., Qi, L., and Deng, L. "Efficiency measurement and decomposition in hybrid two-stage DEA with additional inputs", Expert Systems with Applications, 79, pp. 348-357 (2017).

6. Jakovljevic, M.B., Vukovic, M., and Fontanesi, J. "Life expectancy and health expenditure evolution in Eastern Europe-DiD and DEA analysis", Expert Review of Pharmacoeconomics \& Outcomes Research, 16(4), pp. 537-546 (2016).

7. Farrell, M.J. "The measurement of productive efficiency", Journal of the Royal Statistical Society Series A (General), 120, pp. 253-290 (1957).

8. Charnes, A., Cooper, W.W., and Rhodes, E. "Measuring the efficiency of decision making units", European Journal of Operational Research, 2(6), pp. 429-444 (1978).

9. Banker, R.D., Charnes, A., and Cooper, W.W. "Some models for estimating technical and scale inefficiencies in data envelopment analysis", Management Science, 30(9), pp. 1078-1092 (1984).

10. Chen, Y., Liang, L., and Zhu, J. "Equivalence in twostage DEA approaches", European Journal of Operational Research, 193(2), pp. 600-604 (2009).

11. Lee, T., Zhang, Y., and Jeong, B.H. "A multi-period output DEA model with consistent time lag effects", Computers \& Industrial Engineering, 93, pp. 267-274 (2016).

12. Kritikos, M.N. "A full ranking methodology in data envelopment analysis based on a set of dummy decision making units", Expert Systems with Applications, 77, pp. 211-225 (2017).

13. Fare, R. and Grosskopf, S. "Network DEA", Socio Economics Planning Science, 4(1), pp. 35-49 (2000).

14. Kao, C. "Efficiency decomposition in network data envelopment analysis: A relational model", European Journal of Operational Research, 192(3), pp. 949-962 (2009).

15. Kou, M., Chen, K., Wang, S., et al. "Measuring efficiencies of multi-period and multi-divisionsystems associated with DEA: An application to OECD countries, national innovation systems", Expert Systems with Applications, 46, pp. 494-510 (2016).

16. Kao, C. and Hwang, S.N. "Efficiency decomposition in two-stage data envelopment analysis: An application to non-life insurance companies in Taiwan", European Journal of Operational Research, 185(1), pp. 418-429 (2008).

17. Cook, W.D., and Zhu, J. "Data envelopment analysisa handbook of modeling", Internal Structure and Network, 208, Springer, New York (2014). 
18. Yu, M.M. and Lin, E.T. "Efficiency and effectiveness in railway performance using a multi-activity network DEA model", Omega, 36(6), pp. 1005-1017 (2008).

19. Cook, W.D., Zhu, J., Bi, G., et al. "Network DEA: Additive efficiency decomposition", European Journal of Operational Research, 207(2), pp. 1122-1129 (2010).

20. Liu, J.S., Lu, L.Y., and Lu, W.M. "Research fronts and prevailing applications in data envelopment analysis", In Data Envelopment Analysis, pp. 543-574, Springer, Boston, MA (2016).

21. Fare, R., Grosskopf, S., Lovell, C.K., et al. "Multilateral productivity comparisons when some outputs are undesirable: a nonparametric approach", The Review of Economics and Statistics, 4(1), pp. 90-98 (1989).

22. Seiford, L.M. and Zhu, J. "Modeling undesirable factors in efficiency evaluation", European Journal of Operational Research, 142(1), pp. 16-20 (2002).

23. Jahanshahloo, G.R., Lotfi, F.H., Shoja, N., et al. "Undesirable inputs and outputs in DEA models", Applied Mathematics and Computation, 169(2), pp. 917-925 (2005).

24. Badiezadeh, T. and Farzipoor Saen, R. "Efficiency evaluation of production lines using maximal balance index", International Journal of Management and Decision Making, 13(3), pp. 302-317 (2014).

25. Lu, W.M. and Lo, S.F. "A closer look at the economicenvironmental disparities for regional development in China", European Journal of Operational Research, 183(2), pp. 882-894 (2007).

26. Wang, K., Yu, S., and Zhang, W. "China's regional energy and environmental efficiency: A DEA window analysis based dynamic evaluation", Mathematical and Computer Modelling, 58(5-6), pp. 1117-1127 (2013).

27. Wu, J., Lv, L., Sun, J., et al. "A comprehensive analysis of China's regional energy saving and emission reduction efficiency: from production and treatment perspectives", Energy Policy, 84, pp. 166-176 (2015).

28. Wu, J., Zhu, Q., Ji, X., et al. "Two-stage network processes with shared resources and resources recovered from undesirable outputs", European Journal of Operational Research, 251(1), pp. 182-197 (2016).

29. Liang, L., Cook, W.D., and Zhu, J. "DEA models for two-stage processes: Game approach and efficiency decomposition", Naval Research Logistics (NRL), 55(7), pp. 643-653 (2008).

30. Li, Y., Chen, Y., Liang, L., et al. "DEA models for extended two-stage network structures", Omega, 40(5), pp. 611-618 (2012).

31. An, Q., Yang, M., Chu, J., et al. "Efficiency evaluation of an interactive system by data envelopment analysis approach", Computers \& Industrial Engineering, 103, pp. 17-25 (2017).

32. Zhou, X., Luo, R., Tu, Y., et al. "Data envelopment analysis for bi-level systems with multiple followers", Omega, 77, pp. 180-188 (2018).
33. Du, J., Zhu, J., Cook, W.D., et al. "DEA models for parallel systems:Game-theoretic approaches", AsiaPacific Journal of Operational Research, 32(02), p. 1550008 (2015).

34. Maiti, S.K. and Roy, S.K. "Bi-level programming for stackelberg game with intuitionistic fuzzy number: A ranking approach", Journal of the Operations Research Society of China, 9(1), pp. 131-149 (2021).

35. Maiti, S.K. and Roy, S.K. "Multi-choice stochastic bilevel programming problem in cooperative nature via fuzzy programming approach", Journal of Industrial Engineering International, 12(3), pp. 287-298 (2016).

36. Roy, S.K. and Maiti, S.K. "Stochastic bi level programming with multi-choice for Stackelberg game via fuzzy programming", International Journal of Operational Research, 29(4), pp. 508-530 (2017).

37. Roy, S.K. and Maiti, S.K. "Reduction methods of type2 fuzzy variables and their applications to Stackelberg game", Applied Intelligence, 50(5), pp. 1398-1415 (2020).

38. Amirteimoori, A. "DEA efficiency analysis: Efficient and anti-efficient frontier", Applied Mathematics and Computation, 186(1), pp. 10-16 (2007).

39. Wang, Y.M. and Chin, K.S. "A new approach for the selection of advanced manufacturing technologies: DEA with double frontiers", International Journal of Production Research, 47(23), pp. 6663-6679 (2009).

40. Azizi, H. and Wang, Y.M. "Improved DEA models for measuring interval efficiencies of decision-making units", Measurement, 46(3), pp. 1325-1332 (2013).

41. Azizi, H. and Ajirlu, H.G. "Measurement of the worst practice of decision-making units in the presence of non-discretionary factors and imprecise data", Applied Mathematical Modelling, 35(9), pp. 4149-4156 (2011).

42. Badiezadeh, T., Saen, R.F., and Samavati, T. "Assessing sustainability of supply chains by double frontier network DEA: A big data approach", Computers \& Operations Research, 98, pp. 284-290 (2018).

43. Doyle, J.R., Green, R.H., and Cook, W.D. "Upper and lower bound evaluation of multiattribute objects: Comparison models using linear programming", Organizational Behavior and Human Decision Processes, 64(3), pp. 261-273 (1995).

44. Entani, T., Maeda, Y., and Tanaka, H. "Dual models of interval DEA and its extension to interval data", European Journal of Operational Research, 136(1), pp. 32-45 (2002).

45. Azizi, H. "DEA efficiency analysis: A DEA approach with double frontiers", International Journal of Systems Science, 45(11), pp. 2289-2300 (2014).

46. Azizi, H., Kordrostami, S., and Amirteimoori, A. "Slacks-based measures of efficiency in imprecise data envelopment analysis: An approach based on data envelopment analysis with double frontiers", Computers \& Industrial Engineering, 79, pp. 42-51 (2015). 
47. Jahed, R., Amirteimoori, A., and Azizi, H. "Performance measurement of decision-making units under uncertainty conditions: An approach based on double frontier analysis", Measurement, 69, pp. 264-279 (2015).

48. Martins, A.A., Mata, T.M., Costa, C.A., et al. "Framework for sustainability metrics", Industrial \& Engineering Chemistry Research, 46(10), pp. 29622973 (2007).

49. Chen, C., Zhu, J., Yu, J.Y., et al. "A new methodology for evaluating sustainable product design performance with two-stage network data envelopment analysis", European Journal of Operational Research, 221(2), pp. 348-359 (2012).

50. Pope, J., Annandale, D., and Morrison-Saunders, A. "Conceptualising sustainability assessment", Environmental Impact Assessment Review, 24(6), pp. 595-616 (2004).

51. Gerdessen, J.C. and Pascucci, S. "Data envelopment analysis of sustainability indicators of European agricultural systems at regional level", Agricultural Systems, 118, pp. 78-90 (2013).

52. Galán-Martín, Á., Guillén-Gosálbez, G., Stamford, L., et al. "Enhanced data envelopment analysis for sustainability assessment:A novel methodology and application to electricity technologies", Computers \& Chemical Engineering, 90, pp. 188-200 (2016).

53. Zhou, P., Ang, B.W., and Poh, K.L. "A survey of data envelopment analysis in energy and environmental studies", European Journal of Operational Research, 189(1), pp. 1-18 (2008).

54. Hwang, S.N., Chen, C., Chen, Y., et al. "Sustainable design performance evaluation with applications in the automobile industry: Focusing on inefficiency by undesirable factors", Omega, 41(3), pp. 553-558 (2013).

55. Wang, W.K., Lu, W.M., and Liu, P.Y. "A fuzzy multi-objective two-stage DEA model for evaluating the performance of US bank holding companies", Expert Systems with Applications, 41(9), pp. 42904297 (2014).

56. Yousefi, S., Soltani, R., Saen, R.F., et al. "A robust fuzzy possibilistic programming for a new network GPDEA model to evaluate sustainable supply chains", Journal of Cleaner Production, 166, pp. 537-549 (2017).

57. Shabanpour, H., Yousefi, S., and Farzipoor Saen, R. "Future planning for benchmarking and ranking sustainable suppliers using goal programming and robust double frontiers DEA", Transportation Research Part D: Transport and Environment, 50, pp. 129-143 (2017).
58. Leleu, H., Moises, J., and Valdmanis, V.G. "How do payer mix and technical inefficiency affect hospital profit? A weighted DEA approach", Operations Research for Health Care, 3(4), pp. 231-237 (2014).

59. Asandului, L., Roman, M., and Fatulescu, P. "The efficiency of healthcare systems in Europe: A data envelopment analysis approach", Procedia Economics and Finance, 10, pp. 261-268 (2014).

60. Hamid Abu Bakar, A., Lukman Hakim, I., Choy Chong, S., et al. "Measuring supply chain performance among public hospital laboratories", International Journal of Productivity and Performance Management, 59(1), pp. 75-97 (2009).

61. Patra, A., and Ray, P.K. "Measurement of efficiency and productivity growth of hospital systems: A Indian case study", In Healthcare Systems Management: Methodologies and Applications, pp. 13-22, Springer, Singapore (2018).

62. Cheng, C.H. and Lin, Y. "Evaluating the best main battle tank using fuzzy decision theory with linguistic criteria evaluation", European Journal of Operational Research, 142(1), pp. 174-186 (2002).

63. Korhonen, P.J. and Luptacik, M. "Eco-efficiency analysis of power plants: An extension of data envelopment analysis", European Journal of Operational Research, 154(2), pp. 437-446 (2004).

64. Charnes, A. and Cooper, W.W. "Programming with linear fractional functional", Naval Research Logistics Quarterly, 9(3-4), pp. 181-186 (1962).

65. Wang, Y.M., Greatbanks, R., and Yang, J.B. "Interval efficiency assessment using data envelopment analysis", Fuzzy Sets and Systems, 153(3), pp. 347-370 (2005).

\section{Biography}

Ehsan Vaezi received $\mathrm{PhD}$ in Industrial Engineering from Science and Research branch, Islamic Azad University, Tehran, Iran in 2009. He obtained his BS in Electrical Engineering from Iran University of Science and Technology (2009) and his MSc in Industrial Engineering from Tehran University (2011). His research interests include game theory, data envelopment analysis, multi-criteria decision-making techniques, and system dynamics. His papers appeared in International Journal of Scientia Iranica, Industrial Engineering and Management Studies, Industrial and Systems Engineering, and other journals of repute. 